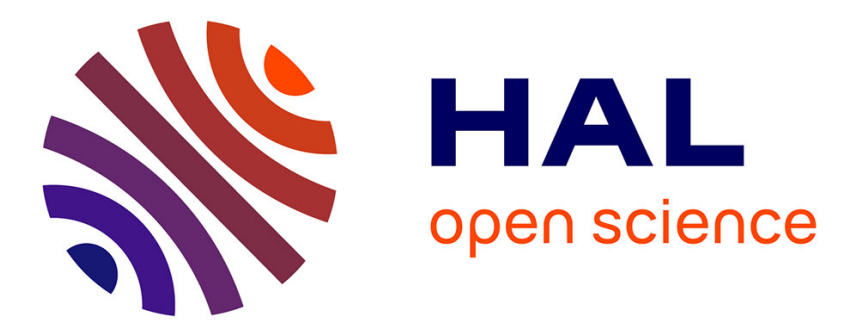

\title{
Validation of FIRETEC wind-flows over a canopy and a fuel-break
}

François Pimont, Jean-Luc Dupuy, Rodman R. Linn, Sylvain Dupont

\section{To cite this version:}

François Pimont, Jean-Luc Dupuy, Rodman R. Linn, Sylvain Dupont. Validation of FIRETEC windflows over a canopy and a fuel-break. International Journal of Wildland Fire, 2009, 18 (7), pp.775-790. 10.1071/WF07130 . hal-02661902

\section{HAL Id: hal-02661902 \\ https://hal.inrae.fr/hal-02661902}

Submitted on 30 May 2020

HAL is a multi-disciplinary open access archive for the deposit and dissemination of scientific research documents, whether they are published or not. The documents may come from teaching and research institutions in France or abroad, or from public or private research centers.
L'archive ouverte pluridisciplinaire HAL, est destinée au dépôt et à la diffusion de documents scientifiques de niveau recherche, publiés ou non, émanant des établissements d'enseignement et de recherche français ou étrangers, des laboratoires publics ou privés. 


\title{
Validation of FIRETEC wind-flows over a canopy and a fuel-break
}

\author{
François Pimont ${ }^{\mathrm{A}, \mathrm{D}}$, Jean-Luc Dupuy ${ }^{\mathrm{A}}$, Rodman R. Linn ${ }^{\mathrm{B}}$ and Sylvain Dupont ${ }^{\mathrm{C}}$ \\ AINRA (Institut National pour la Recherche Agronomique), Unité de Recherches \\ Forestières Méditerranéennes, Equipe de Prévention des Incendies de Forêt, \\ UR629, F-84914, Avignon, France. \\ BEarth and Environmental Sciences Division, Los Alamos National Laboratory Los Alamos, \\ NM 87544, USA. \\ CINRA, UR1263 EPHYSE, 71 Avenue Edouard Bourlaux, F-33883, Villenave d'Ornon, France. \\ DCorresponding author. Email: pimont@avignon.inra.fr
}

\begin{abstract}
The wildfire model FIRETEC simulates the large coherent eddies of the wind-flows induced by the canopy. It has been qualitatively validated in its ability to simulate fire behavior, but there is still a need to validate physical submodels separately. In the present study, the dynamics and turbulence of the flow simulated by FIRETEC are validated in a manner similar to other air-flow models without fire, through comparison with measurements associated with flows within continuous and discontinuous forests captured through in situ and wind-tunnel experiments with neutral thermal stratification. The model is shown to be able to reproduce accurately all essential features of turbulent flow over both forests. Moreover, a short sensitivity study shows that the model is not very sensitive to uncertain parameters such as vegetation drag coefficient. Finally, it is shown in the discontinuous forest case that wind gusts on fuel-breaks can be very strong and significantly higher than in surrounding canopies, even if their directions are more stable. These results and others briefly reviewed in the present paper allow better understanding of wind-flow perturbations induced by fuel-breaks. This new validation added to previous ones confirms the ability of FIRETEC for investigating effects of fuel-break design on fire propagation.
\end{abstract}

Additional keywords: forest canopy, forest edge, HIGRAD, large-eddy simulation, wildfire.

\section{Introduction}

It is well known that wildfire propagation is closely linked to the wind-flow dynamics and turbulence within and above the forest canopy (i.e. the fuel-bed). Several experiments have shown that the fire spread is strongly correlated with mean wind velocity (see, for example, Cheney et al. 1998). Wind flow is indeed responsible for convective cooling and advection of hot gaseous species; it also plays a critical role in determining turbulent mixing within the flame and is likely to influence the balance between different modes of heat transfer (convective and radiative). At local scales, the wind-flow dynamics and wildfire propagation are all the more complex as the fuel-bed is heterogeneous owing to, for example, the presence of clearings, fuel-breaks, clumping at tree scale and undergrowth. Hence, modelling turbulent wind fields accurately over heterogeneous landscapes is crucial in fire propagation models. The computation of more accurate wind flows has been shown to result in improvements of fire behaviour model predictions (Butler et al. 2006).

Wildfire models range from the empirical to conglomerations of theoretical representations of physical processes that drive wildfires. Winds are incorporated into these models in different ways depending on the basis behind the model development. In some empirical models, the mean non-fire-influenced wind at specific heights is used. It can be the average wind speed at midflame height (see, for example, the BEHAVE model in Andrews 1986), or the 10-m-height wind speed measured from meteorological stations. The appropriate reference wind speed is not easy to define (Linn and Cunningham 2005) and is influenced by the local environment, including fire and fuel discontinuities. The modifications of wind-field dynamics and turbulence regimes due to fuel discontinuities are usually not explicitly considered. Additionally, the empirical laws of fire used by some of these models are deduced from laboratory experiments (Rothermel 1972; Catchpole et al. 1998), where turbulence conditions can be very different from turbulence generated in field canopies. However, some of the models are based on representing the physical processes that drive wildfires including coupled atmosphere-fire interaction and wind interaction with canopies. In these models, the determination of fire behavior (spread, intensity, etc.) depends on physical processes occurring within and above the vegetation. The present paper is focussed on one of these coupled atmosphere-fire models.

Without wildfires, the wind-flow dynamics and turbulence over homogeneous canopies are reasonably well understood for neutral thermal stratification; they are analogous to a plane mixing-layer flow (Raupach et al. 1996). The mean flow is characterized by a strong wind shear at canopy top associated 
with an inflection point in the mean horizontal velocity profile, and a rapid decrease of turbulent kinetic energy and momentum flux with depth in the canopy (see, for example, Brunet et al. 1994; Kaimal and Finnigan 1994; Raupach et al. 1996; Finnigan 2000). The inflection point is responsible for the development of large coherent eddies that control most of the momentum and scalar transfer between vegetation and the atmosphere (Gao et al. 1989; Lu and Fitzjarrald 1994). These large coherent structures are characterized by cycles of strong 'sweeps' (gusts) into the canopy and weak 'ejections' (bursts) vertically out of the top of the canopy. Their length scales are on the order of the canopy height. The presence of sudden canopy heterogeneities induces additional turbulence, acceleration of the wind, and consequently increases gust intensity (Dupont and Brunet 2006). In a wildfire context, the interaction between large coherent structures and fire is not well understood. However, it seems reasonable to speculate that the presence of such eddy structures may influence fire propagation at the fuel-bed scale as well as at the tree scale by increasing the vertical transport from the ground (or undergrowth) to the canopy top and conversely.

In order to reproduce the observed characteristics of turbulent flow over vegetated canopies, various types of computational fluid dynamics (CFD) models have been developed over the last decade, using a range of turbulent schemes. These particular CFD models are designed to be able to assess mass, momentum and energy exchanges at the canopy-atmosphere interface. Several low-order closure schemes have been applied to simulate air flow over vegetation canopies (Li et al. 1990; Green 1992; Liu et al. 1996; Foudhil et al. 2005). However, these Reynoldsaveraged-type models only simulate mean fields and do not allow the canopy turbulence to be resolved. Without resolving this turbulence, it is difficult to analyse the turbulent structures in as great a detail as is possible with large-eddy simulation (LES). With LES techniques, eddy motions of order twice the grid mesh size and larger are explicitly solved, whereas subgridscale eddy motions are modelled. Provided that the grid is fine enough, an LES technique allows one to have access to instantaneous dynamical fields and is therefore capable of resolving wind gusts in a plant canopy, as well as large coherent eddy structures, which may be crucial in wildfire propagation. LES has been successfully applied over various homogeneous (Shaw and Schumann 1992; Kanda and Hino 1994; Su et al., 1998, 2000; Watanabe 2004; Dupont and Brunet 2008a) and heterogeneous (Patton et al. 1998; Yang et al. 2006a, 2006b; Dupont and Brunet 2007) vegetation canopies under essentially neutral stratification.

The wildfire model FIRETEC (Linn 1997) is a threedimensional, physically based model coupled to the atmospheric transport HIGRAD model (Reisner et al. 2000a, 2006b). HIGRAD computes compressible fluid flow in the lower atmosphere, solving Navier-Stokes equations with an LES approach. The model is based on the MPDATA for the advection scheme (Smolarkiewicz and Margolin 1998) and is second-order accurate in time and space. FIRETEC includes a multiphase representation of vegetation in order to simulate mass, momentum, and energy exchange between solid fuels and gases during fire propagation at multiple-metre scales. Terms such as radiative and convective heat transfer and combustion have been included in order to account for interactions between fire, air flow and vegetation. Although HIGRAD was previously validated for some scenarios, including urban areas, through comparison with laboratory data and urban field experiments by explicitly representing buildings (Smith et al. 2001, 2002), the validation of wind fields produced by the HIGRAD/FIRETEC modelling system with its multiphase interaction between air flow and vegetation canopy has never been published, and is the subject of the present paper.

Two approaches are possible to evaluate the performance of such a physics-based wildfire model. The first approach is to validate the global behavior of the fire model using simple cases. Qualitative data, such as fire behavior or fire-front shape, as well as global quantitative data, such as rate of spread or fire intensity, can be compared with experimental values for various winds, slopes and fuel types. In FIRETEC simulations performed by Linn and Cunningham (2005), the predicted wind effect on the rate of spread (ROS) compared well with the observations of experimental fires over homogeneous grasslands in Australia (Cheney et al. 1998). The more complex situation observed during the crown fires of the International Crown Fires Modelling Experiment (ICFME) was also investigated (Linn et al. 2005b). Although the results were encouraging, local dynamic and thermodynamic variables (gas densities, velocities, temperatures, heat flux) were never validated owing to the difficulty of performing in situ measurements of real fires; indeed, the available field datasets showed considerable variability due to fuel inhomogeneities and turbulent gusts among other reasons (Alexander 1998; Cruz 2004). Experimental works performed at laboratory scales are also difficult to use for FIRETEC validation because the fire itself compromises the use of dimensional analysis and because the model is not designed to represent processes at centimetre scales (FIRETEC mesh sizes are typically $\sim 2 \mathrm{~m}$ ). The second approach to validate wildfire models is to validate and calibrate step by step each part of the model. This approach is of course not possible for all parts of the model because of the difficulty in isolating small portions of the coupled set of physical processes such as heat transfer and combustion that constitute a wildfire.

The goal of the present study is to validate the wind dynamics part of HIGRAD/FIRETEC over vegetated canopies with a neutral thermal stratification and without considering fire propagation or interaction between winds and strong buoyant sources. Although wildfire may often occur under unstable thermal stratifications, applying LES under unstable conditions at a fine scale over vegetation canopy is still very challenging since it would require much more complex physical parameterization such as vegetation and soil energy budgets, which is not the scope of the present paper. This is the subject of ongoing research. In the present paper, a description of the dynamic part of HIGRAD/FIRETEC is provided, then a description of the validation of the mean wind velocity and basic turbulent statistics simulated by the model over a continuous forest canopy using the in situ measurements of Shaw et al. (1988). The model is then validated over a discontinuous forest using the wind-tunnel measurements of Raupach et al. (1987). The discontinuous forest case suggests some conclusions on the role of fuelbreaks in fire propagation through an analysis of the wind-flow characteristics. 


\section{Model description}

The HIGRAD/FIRETEC modelling system is a threedimensional, two-phase transport model where conservation equations of mass, momentum, energy and chemical species are written in terrain-following coordinates. A detailed description of the physical and chemical formulation of the model is available in Linn (1997), Linn et al. (2002) and Linn and Cunningham (2005). HIGRAD's solver is based on a conservative forwardin-time numerical technique (Reisner et al. 2000a, 2000b). FIRETEC includes a multiphase representation of vegetation with a drag-force approach; a pressure and viscous drag-force term in the momentum equation is included, as well as a sink term in equations for subgrid-scale turbulent kinetic energy in order to represent the acceleration of the dissipation of turbulent eddies in the inertial subrange. The technique used to resolve conservation equations is similar to an LES. Eddy motions larger than twice the grid mesh are explicitly solved through conservation equations, whereas subgrid-scale eddy motions are modelled. Provided that the grid is fine enough, the model allows one to have access to instantaneous dynamical fields and is capable of reproducing wind gusts in a plant canopy.

Hence, the momentum equation is filtered to separate small and large scales. The resulting equations can therefore be seen as grid mass-averaged equations. The momentum equation is written as:

$$
\frac{\partial}{\partial t}\left(\rho_{g} \tilde{u}_{i}\right)+\frac{\partial}{\partial x_{j}}\left(\rho_{g} \tilde{u}_{i} \tilde{u}_{j}\right)=-\frac{\partial p}{\partial x_{j}}+\rho_{g} g_{i}-\frac{\partial R_{i j}}{\partial x_{j}}+F_{d i}
$$

where the tilde indicates resolved mass-weighted averaged variables, $\rho_{g}$ is the gas density, $u_{i}$ the gas velocity component in the $i$ direction ( $i=1,2$ and 3 for the $x, y$ and $z$ or streamwise, spanwise and vertical directions respectively), $\rho$ is the pressure, $g_{i}$ the gravitational acceleration in the $i$ direction and $F_{d i}$ the drag force component in the $i$ direction. The turbulent Reynolds stress tensor $R_{i j}=\rho_{g} u_{i}^{\prime \prime} u_{j}^{\prime \prime}$ represents the correlation between velocity departures from the resolved field or subgrid-scale velocities (double primes variables) in the $i$ and $j$ directions. The terms on the right-hand side of Eqn 1 represent respectively the pressuregradient force, buoyancy, turbulence diffusion and the drag force induced by the vegetation. This latter term is modelled as follows using the Tensor summation convention:

$$
F_{d i}=-C_{d} a_{f} \sqrt{\tilde{u}_{k} \tilde{u}_{k}} \tilde{u}_{i}
$$

where $C_{d}$ is the drag coefficient of the vegetation canopy and $a_{f}$ the vegetation frontal area density, equal to $\alpha \sigma / 2$, where $\alpha$ is the volume fraction and $\sigma$ is the area per unit volume of leaves or needles.

All turbulent structures larger than the largest specified turbulent length scale are explicitly solved by the model, especially turbulent eddies produced by wind shear at canopy top, whereas smaller turbulent structures (i.e. subgrid-scale (SGS) turbulent motions such as vegetation wake eddies) are modelled. Most LES models applied at the vegetation canopy scale compute these SGS turbulent motions through a 1.5-order turbulence closure scheme that solves an SGS turbulent kinetic energy (TKE) conservation equation (see for example Watanabe 2004, or Dupont and Brunet 2008a). The turbulent length scale characterizing the SGS eddies in these models is usually equivalent to the grid spacing. In the context of wildfires, we expect that complex SGS TKE transformations occur at various spatial and temporal scales within subgrids. For this reason, three length scales of turbulence, $s_{A}, s_{B}$ and $s_{C}$, are considered in FIRETEC, each one being associated to an $\operatorname{SGSTKE~}\left(k_{A}, k_{B}\right.$ and $k_{C}$ respectively) conservation equation. This approach is equivalent to splitting SGS TKE into three frequency bands. Shaw and Patton (2003) developed a similar approach in order to focus on vegetation wake TKE by splitting SGS TKE into two frequency bands. In FIRETEC, this approach is developed in order to estimate the TKE at a fine scale $\left(s_{C}\right)$ that is used for computing the reaction rate in the fire model. The two other length scales, $s_{A}$ and $s_{B}$, are respectively the largest unresolved scale and the scale where wake structures are significant. Hence, the total Reynolds stress tensor $R_{i j}$ is calculated using the Boussinesq approximation from the three considered frequency bands referenced by the subscripts $A, B$ and $C$ :

$$
R_{i j}=R_{i j, A}+R_{i j, B}+R_{i j, C}
$$

with

$$
\begin{aligned}
R_{i j, A, B, C}= & \frac{2}{3} \delta_{i j} \rho_{g}\left(v_{T, A, B, C} \frac{\partial \tilde{u}_{k}}{\partial x_{k}}+k_{A, B, C}\right) \\
& -\rho_{g} v_{T, A, B, C}\left(\frac{\partial \tilde{u}_{i}}{\partial x_{j}}+\frac{\partial \tilde{u}_{j}}{\partial x_{i}}\right)
\end{aligned}
$$

where $\delta_{i j}$ is the Kronecker symbol ( $\delta_{i j}$ equals 1 for $i=j$, and 0 otherwise); $v_{T}$ is the total turbulent diffusion coefficient.

The total SGS TKE is given by:

$$
k=k_{A}+k_{B}+k_{C}
$$

Note that some modifications in the turbulence model have been implemented since Linn and Cunningham (2005). As all simulations in the present study were performed under neutral condition over a flat terrain, subgrid-scale TKE equations presented hereafter are written for a neutral atmosphere, for the sake of simplicity. SGS TKE at scale $A\left(k_{A}\right)$ takes into account the transfer of energy present in the mean winds above the canopy due to the main structures of plants composing the canopy:

$$
\frac{\partial \rho_{g} k_{A}}{\partial t}+\frac{\partial \rho_{g} \tilde{u}_{i} k_{A}}{\partial x_{j}}=D_{A}+P_{S, A}-\varepsilon_{A}-E T_{A \rightarrow B}
$$

where $D, P_{S}, \varepsilon$ and $E T_{A \rightarrow B}$ are respectively the diffusion term of the SGS turbulent kinetic energy, the shear production term, the turbulent kinetic energy dissipation rate and the energy transfer from scale $A$ to scale $B$.

The second term on the left-hand side of Eqn 6 represents the advection of $k_{A}$ by the resolved flow, and the terms on the right-hand side represent respectively the turbulent transport diffusion of $k_{A}$, the dynamic shear production coming from resolved scales to SGS, the dissipation of $k_{A}$ and the cascade of $k_{A}$ (see Appendix 1 for the expression of these terms). The cascade term for SGS TKE $\left(E T_{A \rightarrow B}\right)$ represents a transfer of energy from eddies at scale $A$ to eddies at scale $B$ that accentuates the dissipation of turbulence in the canopy compared with the free air due to the interaction of eddies with vegetation. The inertial eddycascade is therefore bypassed (Finnigan 2000). The formulation 
of this term is equivalent (i) to the TKE transfer term from SGS to wake TKE considered in Shaw and Patton's (2003) model with a coefficient of 4 instead of 8/3 (see Appendix 1); and (ii) to the eddy cascade term used in LES models using only one SGS TKE conservation equation with a smaller coefficient (usually 2) in order to consider also the effect of wake eddies that accentuate SGS TKE dissipation (Shaw and Patton 2003).

Eddies at scale $B\left(s_{B}\right)$ depend on the smallest vegetation structures (branch size). The conservation equation of SGS TKE $\left(k_{B}\right)$ at this scale (Eqn 7) is very similar to the $k_{A}$ equation, except (i) the $E T_{A \rightarrow B}$ term has a positive sign, indicating that energy is being transferred from $k_{A}$ to $k_{B}$; (ii) a transfer term $E T_{B \rightarrow C}$ from $B$ to $C$ scales (similar to $E T_{A \rightarrow B}$ ) is included as well as a wake SGS TKE production term $P_{W}$ due to wake eddies induced by small vegetation elements such as branches, leaves or needles (see Appendix 1 for the expression of right-hand-side terms of Eqn 7).

$\frac{\partial \rho_{g} k_{B}}{\partial t}+\frac{\partial \rho_{g} \tilde{u}_{i} k_{B}}{\partial x_{j}}=D_{B}+P_{S, B}-\varepsilon_{B}+E T_{A \rightarrow B}-E T_{B \rightarrow C}+P_{W}$

The last scale $C\left(s_{C}\right)$ is the scale of clumping of particles (shoot of leaves or needles). The SGS TKE of eddies at this scale, $k_{C}$, is simply taken to be proportional to $k_{B}$ as eddies at both scales $B$ and $C$ are statistically produced in the same vicinity (Linn and Cunningham 2005):

$$
k_{C}=0.2 k_{B}
$$

The turbulent diffusion coefficient is calculated according to the Prandtl and Kolmogorov formulation (Pope 2000) and by assuming that SGS turbulent diffusion is isotropic (Eqn 9). This latter assumption may not be valid in presence of a fire or under non-neutral conditions, and for the grid cell size considered in this study but the use of an anisotropic formulation in this particular case would have been too speculative.

$$
v_{T, n}=0.09 s_{n} k_{n}^{1 / 2} \text { (where } n \text { could be } A, B \text { or } C \text { scale) }
$$

The total turbulent diffusion coefficient is given by:

$$
v_{T}=v_{T, A}+v_{T, B}+v_{T, C}
$$

\section{Model validation on a continuous forest}

To test the ability of HIGRAD/FIRETEC to simulate the dynamic and turbulent flow fields over homogeneous canopy in neutral atmospheric conditions, we used the mean wind velocity and standard turbulent statistics profiles measured in near neutral conditions by Shaw et al. (1988) within and above a deciduous forest at Camp Borden in Ontario, Canada. These measurements are consistent with others from wind-tunnel and field campaigns (Raupach et al. 1986; Brunet et al. 1994; Kaimal and Finnigan 1994; Finnigan 2000), and have already been used by Shaw and Schumann (1992), Su et al. (1998) and Dupont and Brunet (2008a) to validate their LES air-flow models.

\section{Numerical details}

The size of the computational domain for the validation simulations was $200 \times 150 \times 615 \mathrm{~m}$ (see Fig. 1) with a horizontal grid

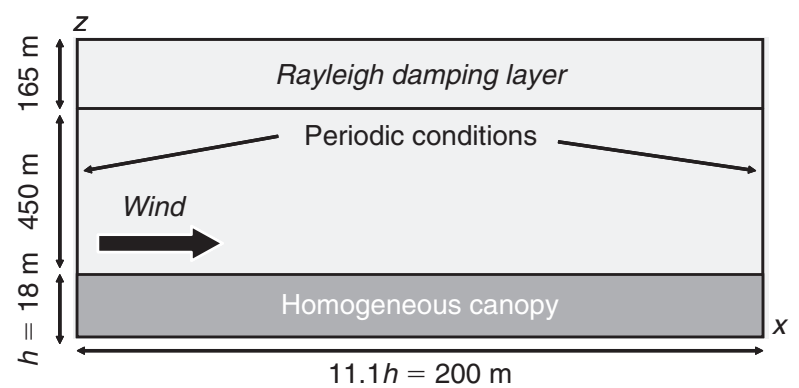

Fig. 1. Schematic representation of the computational domain used in homogeneous canopy simulations.

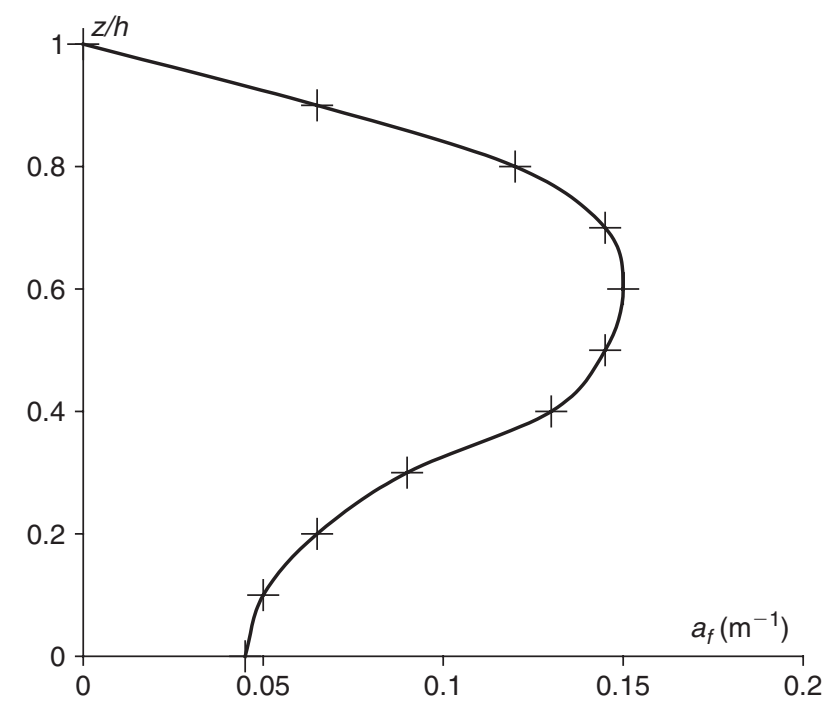

Fig. 2. Frontal area density profile $a_{f}$ of the vegetation used in homogeneous canopy simulations.

spacing of $2 \mathrm{~m}$. The mesh was stretched in the vertical direction, starting from $1.5-\mathrm{m}$ grid spacing near the ground to $40 \mathrm{~m}$ at the top. The canopy height was set at $h=18 \mathrm{~m}$. The frontal area density profile $a_{f}$ was characterized by a lower density within the trunk space (see Fig. 2), and the drag coefficient $C_{d}$ was set to 0.25 . The initial wind flow was considered in equilibrium with the ground, which means that the initial velocity profile was logarithmic. Its direction was parallel to the $x$ axis. Consequently, wind velocity profiles were initialized as follows:

$$
u_{1}^{i n i}(z)=u_{2 h}^{i n i} \frac{\log (z)}{\log (2 h)}, \quad u_{2}^{i n i}(z)=u_{3}^{i n i}(z)=0
$$

where the superscript ini indicates initial value. Additionally, the vertical profile of potential temperature was constant and equal to $300 \mathrm{~K}$, and the atmosphere was dry.

In the reference simulation, denoted as hom0, the initial wind velocity $u_{2 h}^{i n i}$ at $2 h$ above the surface was equal to $2.75 \mathrm{~m} \mathrm{~s}^{-1}$ and turbulent scales $s_{A}, s_{B}$ and $s_{C}$ were set to $2 \mathrm{~m}$ (close to the average grid size near the ground), $1 \mathrm{~m}$ and $0.25 \mathrm{~m}$ respectively. The initial wind velocity was selected so that the mean velocity obtained after simulation convergence was close to the observed values. Some problems related to the use of Dirichlet boundary conditions for simulating flows in canopies with physically based 
Table 1. Description of the four numerical simulations performed over the homogeneous canopy

\begin{tabular}{|c|c|c|}
\hline & $\begin{array}{l}\text { Drag coefficient } \\
\qquad C_{d}\end{array}$ & $\begin{array}{l}\text { Initial wind at } 2 h \text { in } \mathrm{m} \mathrm{s}^{-1} \\
\qquad u_{2 h}^{i n i}\end{array}$ \\
\hline hom0 (Ref) & 0.25 & 2.75 \\
\hline hom 1 & 0.16 & 2.5 \\
\hline hom 2 & 0.32 & 3 \\
\hline hom 3 & 0.25 & 6 \\
\hline
\end{tabular}

models were already mentioned in Pimont et al. (2006). The use of such boundary conditions generates wind velocity and TKE fields that are not realistic with an unrealistically strong inflection in the vertical profile of the streamwise velocity. In response to this problem, we used cyclic conditions on lateral boundaries in the $x$ direction, as usually used in LES models. A Rayleigh damping layer was used at the upper boundary as well as at lateral boundaries in the $y$ direction in order to absorb propagating wave disturbances and to eliminate wave reflection at the boundaries.

Three additional simulations similar to hom 0 were performed in order to study the sensitivity of model results to the drag coefficient value $\left(C_{d}\right)$ and to the wind velocity intensity at $2 h\left(u_{2 h}^{i n i}\right)$. Table 1 presents differences between these additional simulations. In summary, simulations hom 1 and hom 2 were performed with a drag coefficient $C_{d}$ equal to 0.16 and 0.32 respectively, which represents the classical range of variation of $C_{d}$ : between 0.15 and 0.37 following Amiro (1990), Gillies et al. (2002) and Shaw and Patton (2003). In the three first simulations (hom0, hom 1 and hom 2), $u_{2 h}^{\text {ini }}$ was chosen between 2.5 and $3 \mathrm{~m} \mathrm{~s}^{-1}$ in order to obtain mean wind profiles of similar magnitude (before normalization) to observations, while simulation hom 3 was performed with a higher initial wind velocity, $u_{2 h}^{i n i}=6 \mathrm{~m} \mathrm{~s}^{-1}$.

Each simulation was run on 50 processors for 50 to $80 \mathrm{~h}$ of wall-clock time. Since no fire propagation was considered in our simulation, the flow reached an equilibrium state. Wind velocity and turbulence statistics profiles were computed from a timeaveraging procedure (recognized hereafter by the symbol \langle\rangle$_{t}$ ), which was performed between 3000 and $6500 \mathrm{~s}$ (when the simulations had reached a quasi steady-state) with a 0.02 -s interval between realizations for the averaging procedure. Consequently, resolved wind velocity components $\tilde{u}_{i}$ can be decomposed into $\tilde{u}_{i}=\left\langle\tilde{u}_{i}^{\prime}\right\rangle_{t}+\tilde{u}_{i}^{\prime}$, and the prime the deviation from the averaged value. The mean total TKE $\left(k_{t o t}\right)$ and $u$-momentum flux $\left(u^{\prime} w_{t o t}^{\prime}\right)$ profiles were computed as follows:

$$
\begin{gathered}
k_{t o t}=0.5\left\langle\tilde{u}_{i}^{\prime} \tilde{u}_{i}^{\prime}\right\rangle_{t}+\left\langle k_{A}\right\rangle_{t}+\left\langle k_{B}\right\rangle_{t}+\left\langle k_{C}\right\rangle_{t} \\
u^{\prime} w_{t o t}^{\prime}=\left\langle u^{\prime} \tilde{w}^{\prime}\right\rangle_{t}+\left(\left\langle R_{13, A}\right\rangle_{t}+\left\langle R_{13, B}\right\rangle_{t}+\left\langle R_{13, C}\right\rangle_{t}\right) /\left\langle\rho_{g}\right\rangle_{t}
\end{gathered}
$$

Results

Fig. 3 compares the mean vertical profiles of observed and (Fig. $3 a$ ) simulated streamwise wind velocity $\langle\tilde{u}\rangle_{t}$, (Fig. $3 b$ ) total TKE $k_{\text {tot }}$, (Fig. $3 c$ ) total momentum flux $u^{\prime} w_{\text {tot }}^{\prime}$ and (Fig. $3 d, e$, $f$ ) standard deviations of the three wind velocity components $\sigma_{u}$, $\sigma_{v}$ and $\sigma_{w}$ for the reference simulation (hom 0 ). The comparison is only performed through normalized profiles because observed absolute values were not available. Hence, the first three profiles are normalized by their respective value at the canopy top, and the three latter profiles by $\sigma_{h}=\left.\sqrt{2 k_{t o t}}\right|_{(z=h)}$.

Compared with observations, the model performed quite well for all quantities. The model reproduced accurately all essential features of turbulent flow in the vicinity of the homogeneous canopy. Above the canopy, the velocity profile is close to the well-known surface layer logarithmic profile. The simulated TKE and $u$-momentum profiles reach a slight maximum around $z=1.2 h$. An underestimation of predicted turbulence (TKE and $u$-momentum) can be observed at twice the canopy height. At the canopy top, the mean velocity profile is characterized by an inflection point with a strong wind shear before decreasing exponentially within the canopy as trees extract momentum from the flow through drag forces. Within the canopy, TKE and $u$-momentum decay very rapidly with near zero values at the ground for the latter. The partition of TKE into the three spatial directions is accurately reproduced by the model (Fig. $3 d, e$ and $f$ ), with a larger partition in the streamwise direction.

As explained above, the total TKE $\left(k_{t o t}\right)$ is composed of a resolved part $\left(0.5\left\langle\tilde{u}_{i}^{\prime} \tilde{u}_{i}^{\prime}\right\rangle_{t}\right)$ and three modelled parts $\left(k_{A}, k_{B}\right.$ and $\left.k_{C}\right)$. These latter parts are associated with a specific length scale of turbulent structures ranging from 2 to $0.25 \mathrm{~m}$. Fig. 4 compares the contribution of the different parts of the total TKE within the canopy for the reference simulation (hom 0 ). Generally speaking, the contributions of modelled parts are very small compared with the resolved one: they represent less than $10 \%$ of the total TKE. Hence, the simulated flow does not strongly depend on the SGS turbulence scheme. Consequently, for simulations without wildfire under neutral conditions, the decomposition of the SGS TKE into three frequency bands is not necessary. This result confirms previous observations of Shaw and Patton (2003), who showed from their LES model that the role of smaller scales is essentially to enhance the dissipation of subgrid-scale energy, and therefore they may be simply represented through an increase of the cascade term in a unique SGS TKE conservation equation. Consequently, for simulations without wildfire, the decomposition of the SGS TKE into three frequency bands is not necessary under neutral condition. For non-neutral conditions, the utility of such decomposition has not been tested.

Normalized mean wind velocity and turbulence statistics profiles from the three additional simulations (hom1, hom 2 and hom 3) are presented in Fig. 5. Mean profiles were slightly sensitive to the drag coefficient value and to the wind velocity chosen here, especially within the canopy. The differences between the first three runs, hom0, hom 1 and hom 2, can be intuitively connected to differences in drag coefficient values. As the drag coefficient $C_{d}$ is a multiplicative factor of the frontal area density $a_{f}$ of the vegetation, increasing $C_{d}$ is similar to increasing the canopy density. Within the canopy, all turbulent variables (wind velocity, momentum flux, TKE and standard deviation of wind velocity components) were increasingly damped as $C_{d}$ increased, as previously observed from wind-tunnel and numerical experiments (Raupach et al. 1996; Novak et al. 2000; Dupont and Brunet 2008a). This feature indicates that large intermittent eddies do not have sufficient energy to penetrate deep into the canopy with increasing density (Dupont and Brunet $2008 a$ ). With increasing canopy density, large eddies are easier 

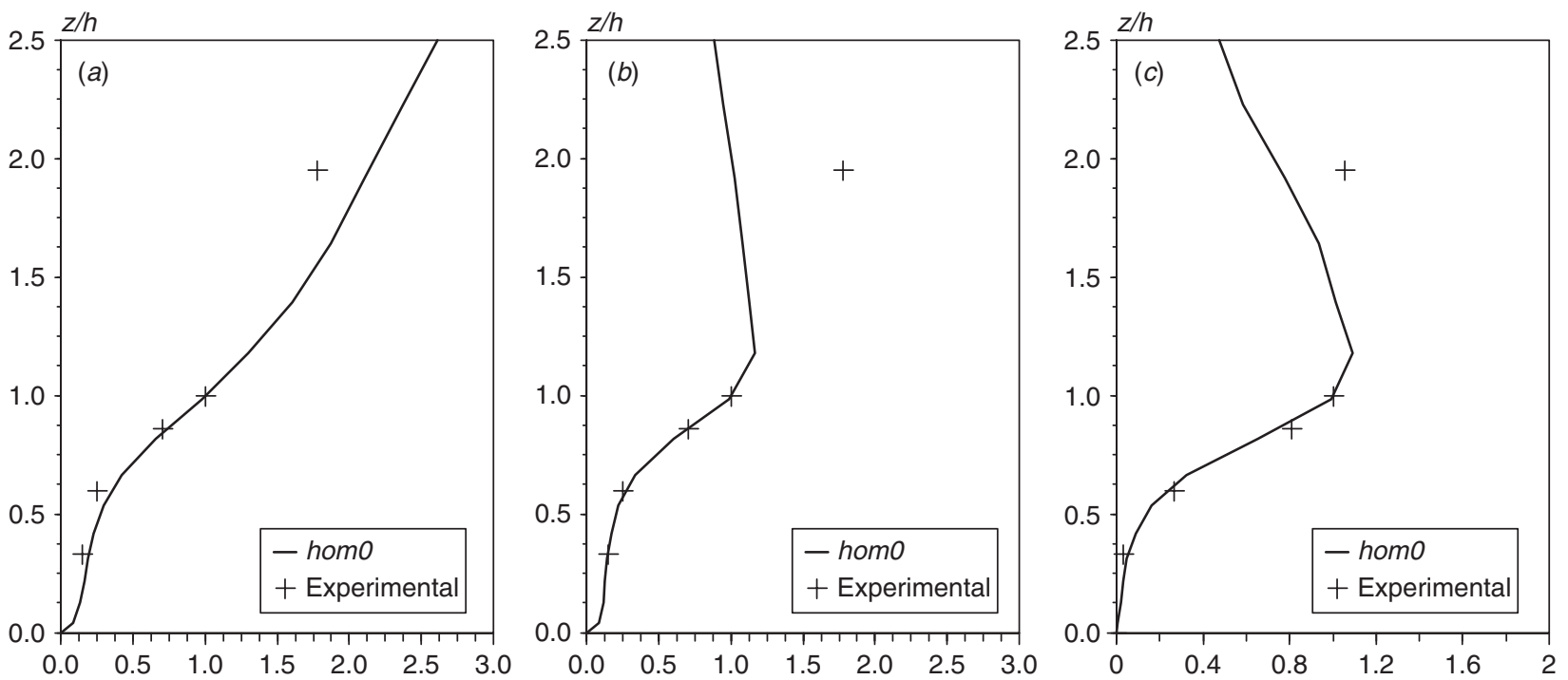

$$
\frac{\langle\tilde{u}\rangle_{t}}{\langle\tilde{u}\rangle_{t(h)}}
$$
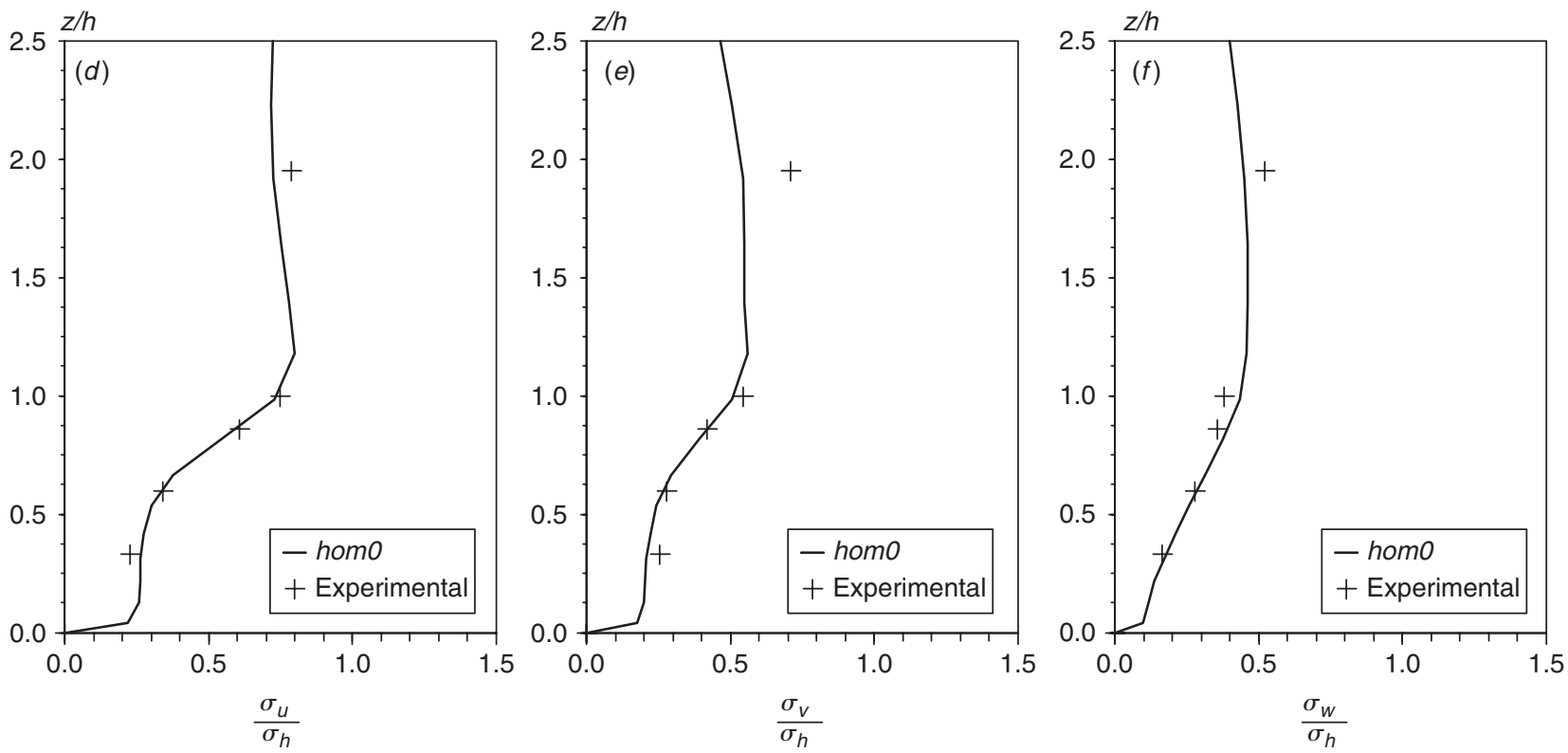

Fig. 3. Validation of HIGRAD/FIRETEC against the field observations of Shaw et al. (1988) in a homogeneous forest canopy (hom0 simulation) Comparison between simulated (lines) and observed (crosses) normalized vertical profiles of mean horizontal wind velocity $(a)$; total turbulent kinetic energy (TKE) $(b)$; momentum flux $(c)$; and standard deviations of the streamwise $(d)$, spanwise $(e)$ and vertical $(f)$ wind components. The first three profiles are normalized by their respective value at the canopy top, and the three latter profiles by $\sigma_{h}=\left.\sqrt{2 k_{t o t}}\right|_{(z=h)}$. The experimental dataset is taken from the paper of Su et al. (1998).

broken into smaller eddies that accentuate turbulence dissipation. As expected, a stronger inflection of the streamwise velocity profile is obtained at the canopy top with the highest drag coefficient (see hom 2 case in Fig. 5a). Above the canopy, variations between profiles are more pronounced than within the canopy. The increase of $C_{d}$ induces smaller wind velocity within the vegetation and larger velocity above it; indeed, vegetation extracts more momentum from the within-canopyflow with increasing density and the upper flow is accelerated by mass conservation. No clear tendency is observed for the other turbulent variables when $C_{d}$ increases. With a larger wind velocity (hom 3 ), momentum flux and TKE are increased above the canopy with a higher maximum than in the reference simulation (hom0), at $z=1.9 h$ instead of $1.2 h$, while they remain similar within the canopy. Compared with observations, all statistical profiles deduced from the additional simulations remain in good agreement; turbulence variables are even better simulated with a higher initial wind velocity (hom 3 simulation). 


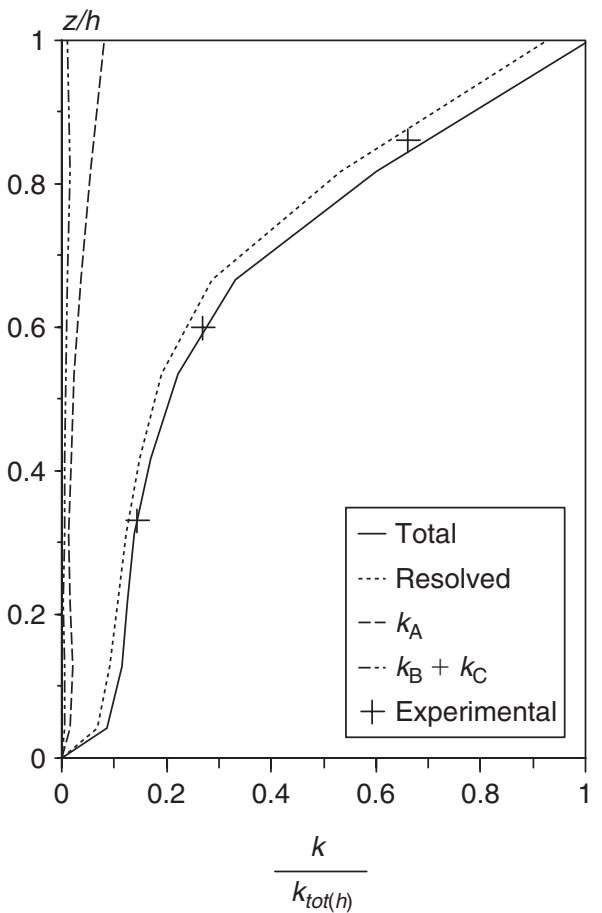

Fig. 4. Comparison between observed and simulated normalized turbulent kinetic energy profiles (total, resolved, subgrid-scale (SGS) at scales $A, B$ and $C$ ) for the reference simulation (hom 0 ).

Initial velocity profiles and more importantly environmental winds in the absorption layer at the top of the domain in hom0, hom 1 and hom 2 were selected so that the magnitude of the mean wind velocity obtained after convergence was close to the nonnormalized experimental one. Thus, in these simulations, the coefficient $\langle\tilde{u}\rangle_{t}(h)$ used to normalize the data was very close to the value used for the experimental data. For hom3, the initial and top velocity used to set the profile $\left(6 \mathrm{~m} \mathrm{~s}^{-1}\right.$ at $35-\mathrm{m}$ height $)$ was at least twice as high as the velocities used in hom0, hom 1 and hom 2. In this case, the mean velocity of the simulated data after convergence was significantly higher than the mean velocity of the experiments; the normalization coefficient was then higher than the coefficient for experimental data. In this case, turbulent statistics (hom 3) show better agreement, even above the canopy.

\section{Model validation on a discontinuous forest}

As stated in the introduction, it is also critical in wildfire models to capture wind-flow perturbations induced by discontinuities in fuel-bed structures such as a break (or clearing). In this section, FIRETEC is validated over a 'canopy-clearing-canopy' configuration from the wind-tunnel dataset of Raupach et al. (1987). In a wildfire context, the clearing can be assimilated as a fuelbreak. Raupach et al. (1987) measured mean wind velocities and turbulence statistics at different distances downwind from the upstream edge of the canopy under neutral stratification. This dataset was previously used by Wilson and Flesh (1999), Foudhil et al. (2005), Yang et al. (2006a) and Dupont and Brunet (2007) to validate their air flow models.

\section{Numerical details}

Simulations were performed in a $300 \times 150 \times 615-\mathrm{m}$ domain with the same spatial resolution as in the homogeneous case. The vegetation canopy was represented by a vertically constant frontal area density equal to $0.17 \mathrm{~m}^{-1}$ with a height of $h=6.5 \mathrm{~m}$. The vegetation was only represented through four layers here compared with the 10 layers used in the previous section in order to minimize (i) the computational cost, and (ii) the aspect ratios of the model grid cells, given that the length of the domain had to be almost 50 times the vegetation height to match experimental conditions. This size of mesh was also chosen to roughly match the usual mesh size used to simulate fires at the landscape scale with FIRETEC. According to the experimental configuration, fuel-break length was $20 h$ and canopy length was $\sim 26 h$ (see Fig. 6). The same initial wind velocity profiles as in the continuous forest were used (Eqn 11), with $u_{2 h}^{i n i}=3 \mathrm{~m} \mathrm{~s}^{-1}$. The other characteristics of the simulation were similar to those used in the previous section for the homogeneous canopy (hom 0 simulation). The averaging procedure performed on the output data was also similar but from an earlier and shorter time period (between 1500 and $3000 \mathrm{~s}$ ) owing to the faster simulation convergence associated to the higher wind velocity.

\section{Results}

The main flow characteristics simulated behind the canopy leading edge were analyzed with observations from Fig. 7 that compare the mean vertical profiles of observed and (Fig. $7 a$ ) simulated streamwise wind velocity $\langle\tilde{u}\rangle_{t}$, (Fig. $7 b$ and $c$ ), standard deviations of the streamwise $\sigma_{u}$ and vertical $\sigma_{w}$ wind velocity and (Fig. 7d) total momentum flux $u^{\prime} w_{t o t}^{\prime}$. All variables are normalized by a reference streamwise velocity $u 2 h$ (equal to $2.5 \mathrm{~m} \mathrm{~s}^{-1}$ ), located at the forest leading edge $(x=0 h)$ and $z=2 h$.

The flow gets distorted when it hits the leading edge of the fuel on the downwind side of the fuel-break. This feature is characterized by a positive vertical velocity as the flow is diverted up and over the trees by the positive pressure gradient resulting from the canopy drag (Fig. 8). The canopy drag also causes a decrease in horizontal velocity downwind from the forest edge (Fig. 7a). The flow accelerates above the canopy. Compared with observations, the vertical profiles of the streamwise wind velocity are accurately simulated at various distances downwind from the leading edge. The vertical velocity above the canopy remains positive until $x=6.4 h$, with maximum values between $x=2.1$ and $4.3 h$ (Fig. 8); then it is approximately zero at $x=10.6 h$ and down to the next forest edge. This is in agreement with Dupont and Brunet (2007), who showed that $10 \mathrm{~h}$ may characterize the length of the adjustment region of the flow with the canopy. Hence, beyond $x=10 h$, all turbulent variables have reached their equilibrium value with the canopy.

The large wind shear at the canopy top (Fig. 7a) induces the development of a region of large turbulence above the canopy observed from the vertical profiles of $\sigma_{u}$ (Fig. $7 b$ ) and $\sigma_{w}$ (Fig. 7c). This region is not readily apparent at the leading edge of the canopy but develops after $x=4.6 h$. Previous studies (Morse et al. 2002; Yang et al. 2006b; Dupont and Brunet 2007) suggested that the development of this turbulent region coincides with the decrease in mean vertical velocity, which is in agreement with the strong decrease observed in simulated vertical 

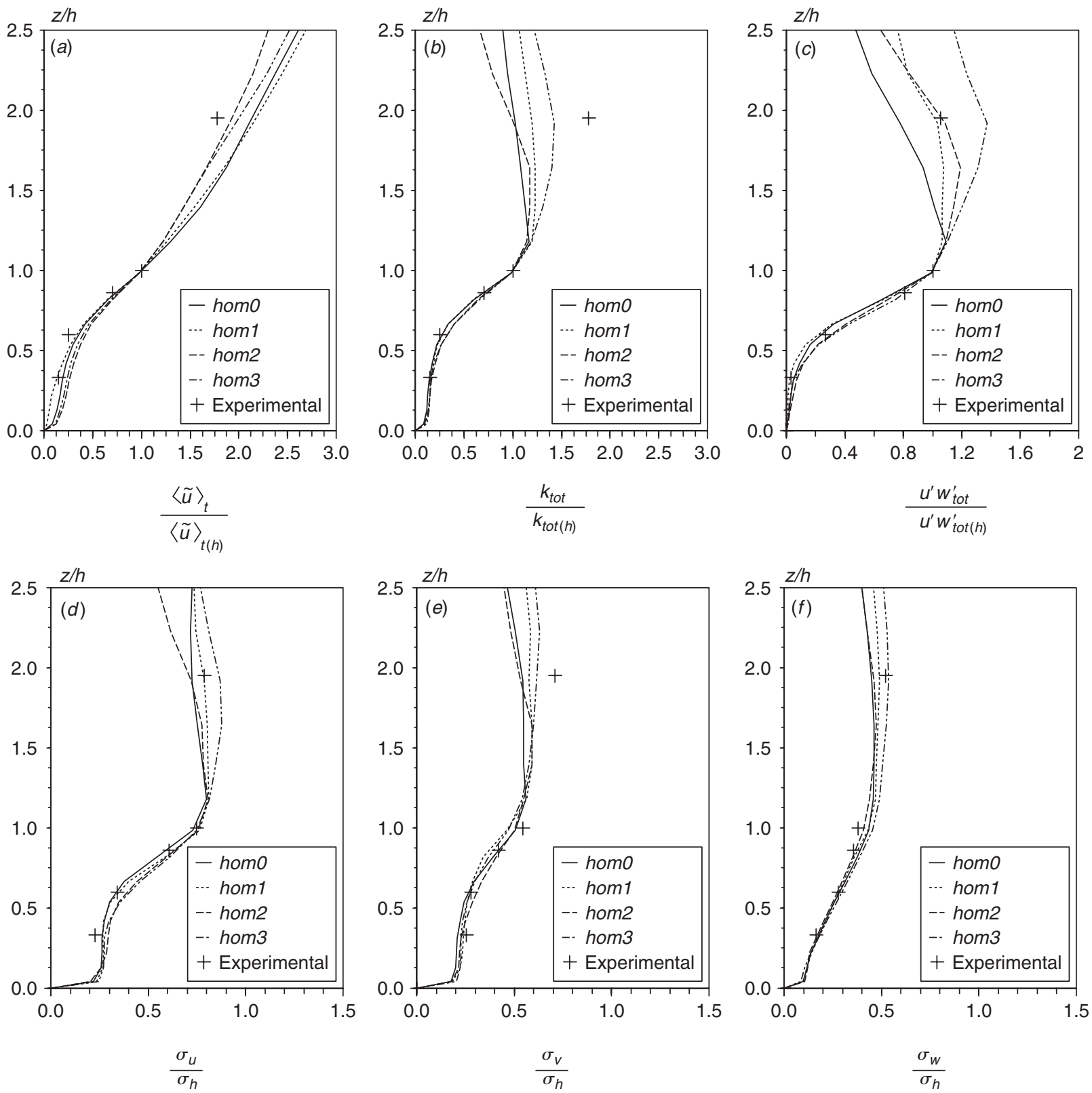

Fig. 5. Same as Fig. 3 but with an additional comparison between the four simulations of the sensitivity study

velocity at $x=6.4 h$ (Fig. 8). The delay from the leading edge of the canopy in the development of this turbulent region above the canopy is explained by the vertical advection of TKE within the adjustment region that transports less turbulent flow from the lower layers toward the top of the canopy. This feature was confirmed by the numerical investigation of the TKE budget of Yang et al. (2006b). The shapes of $\sigma_{u}$ and $\sigma_{w}$ profiles appear well simulated by the model, although $\sigma_{w}$ is slightly underestimated (Fig. 7c). This latter underestimation was not observed in the homogeneous case; it may be explained by the coarser vertical grid resolution used here. The momentum flux $u^{\prime} w_{\text {tot }}^{\prime}$ profiles agree well with experiments, with a small overestimation above the canopy (Fig. $7 d$ ) as also obtained by Yang et al. (2006a) and
Dupont and Brunet (2007) with their LES models. This slight discrepancy may be explained by the use of periodic conditions, since the flow hitting the canopy edge is still affected by the upstream canopy block. More details on the characteristics of turbulent edge flow deduced from LES can be found in Yang et al. (2006b) and Dupont and Brunet (2007).

These results show that the presence of a fuel-break strongly modifies the wind field. The mean wind within the canopy (profile at $x=10.6 \mathrm{~h}$ in Fig. $7 a$ ) is significantly lower than within the break (profile at $x=0 h$ in Fig. 7a). Fig. $9 a$ and $c$ shows the enhancement of the mean wind and total TKE within the fuel-break through their vertical profiles at different distances downwind from the fuel trailing edge $(x=-20 h)$. The increase 


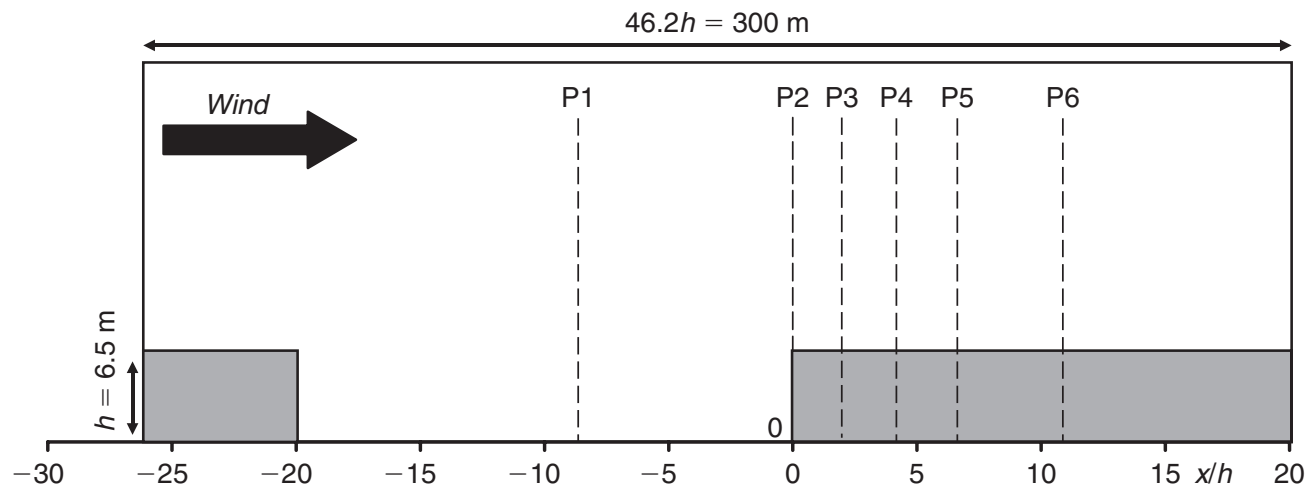

Fig. 6. Schematic representation of the computational domain used for the fuel-break-fuel configuration. Dashed black lines indicate the position of the measured profiles.

in flow speed with distance into the fuel-break is explained by the lower drag force there than in the canopy and a negative vertical flux of higher-velocity winds in the early portion of the fuel-break. The flow is slightly divergent in the break, and the strong wind shear near the tree top is no longer sustained under neutral atmospheric conditions. The large amount of TKE near the tree top is advected downwind from the fuel canopy. The negative vertical velocities (Fig. 9b) transport the turbulent flows from the canopy top to the ground and induce an increase of TKE in the lower layers (Fig. 9c). The flow progressively reaches a new equilibrium with the surface but the length of the break, $20 h$, is not sufficient to observe a fully adjusted flow, which is in agreement with several authors that describe flow equilibrium after several tens of $h$ downwind from a forest trailing edge (Chen et al. 1995; Lee 2000; Dupont and Brunet 2007).

\section{Discussion}

Modelling wind for fire simulation

It follows from the above sections that the wind-flow dynamics simulated by FIRETEC over both continuous and discontinuous forests are very realistic. With the perspective that FIRETEC's main purpose is to simulate fire-atmosphere interactions over heterogeneous landscapes, agreement between the experimental data and the simulation results is good, although some slight discrepancies are present. Pimont et al. (2006) pointed out that non-cyclic boundary conditions for wind computations could provide unrealistic wind profiles. In order to rely on accurate wind data as in the present study for fire simulation, we recommend precomputing wind-flows using cyclic boundary conditions, at least to settle mean and turbulent profiles of the simulation. A use of precomputed wind fields (and not only profiles) as boundary conditions for a fire simulation is probably even better (Canfield et al. 2005). In terms of fire behavior, the large wind fluctuations in the three spatial directions in the case of a canopy could explain a significant part of the lateral ROS of a fire, especially with the presence of a canopy. This effect, as well as the structure of resolved turbulence can only be taken into account in a 3D fire model such as FIRETEC that simulates instantaneous wind fields.

\section{Wind velocity and direction fluctuations within a forest and on a fuel-break}

The intensity of temporal fluctuations of wind speed and direction differs within the canopy and in the fuel-break. Fig. 10 presents 10-min time series of the streamwise wind speed and wind direction at $2.3 \mathrm{~m}(z=0.35 h)$ above the ground within the canopy (at $x=10.4 h)$ and in the fuel-break $(x=-8.5 h)$. The magnitudes of the mean and fluctuating parts of the wind speed are significantly higher within the break than within the canopy owing respectively to extraction by trees of momentum from the flow through drag forces and to the presence of small wake eddies that accentuate turbulence dissipation. Maximum streamwise wind speeds can be seven times higher within the vegetation break than within the canopy. However, fluctuations of the wind directions are much higher within the canopy, with variations of almost $180^{\circ}$ in less than $2 \mathrm{~min}$. This large variability of the wind direction within the canopy is explained not only by the low wind speed, but also by the passage of large coherent eddy structures generated by the canopy and scaling with $h$, which induces local recirculation close to the ground. As stated in the Introduction section, these structures have been the subject of many research efforts for many years, and their development is similar to the development of the structures in a plane-mixing layer flow. They result from the development of Kelvin-Helmholtz instabilities at the canopy top due to the presence of an inflexion point in the mean velocity profile. To illustrate the variability of the wind velocity and direction, Fig. 11 shows two vertical slices of the instantaneous streamwise wind velocity separated by $220 \mathrm{~s}$. These two plots show that in less than $5 \mathrm{~min}$, the wind conditions are totally different. A zoom on some selected zones of the plot at time $=2560 \mathrm{~s}$ (top view, side views near the trailing edge and downwind to the leading edge) illustrates the presence of coherent structures of several $h$ on Fig. 12. Fig. 11 illustrates wind fluctuations over a time period on the order of the duration of experimental fires done in the field $(10 \mathrm{~min})$. It shows that the wind environment is likely to change very significantly during a single fire experiment. It also shows the difficulties in repeating 

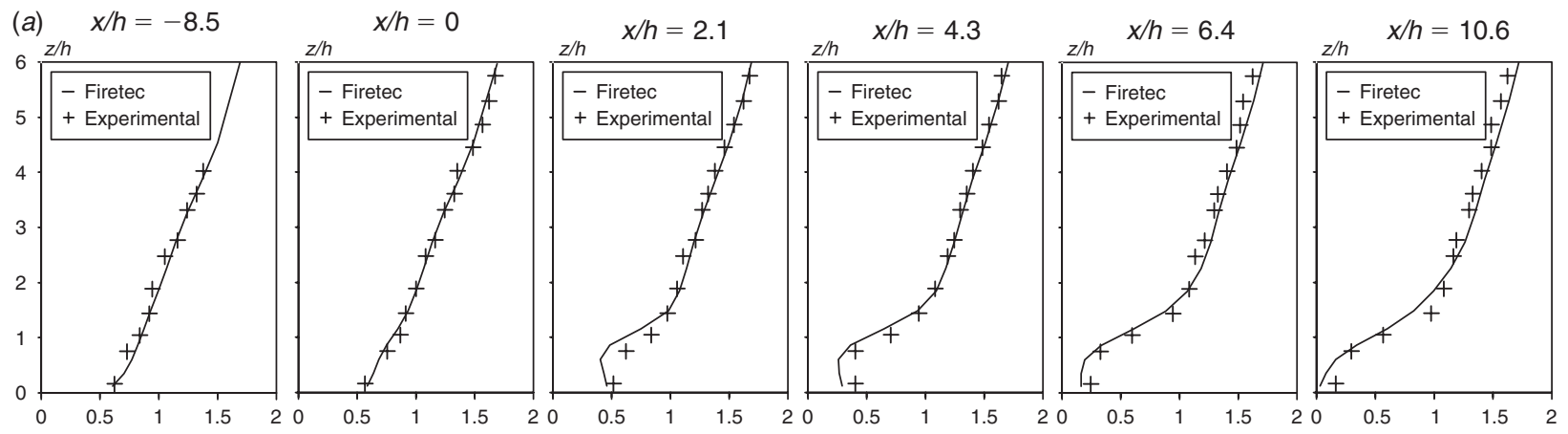

(b)

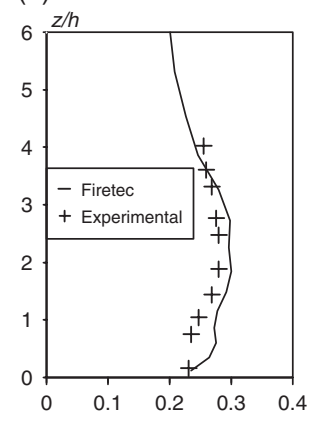

(c)
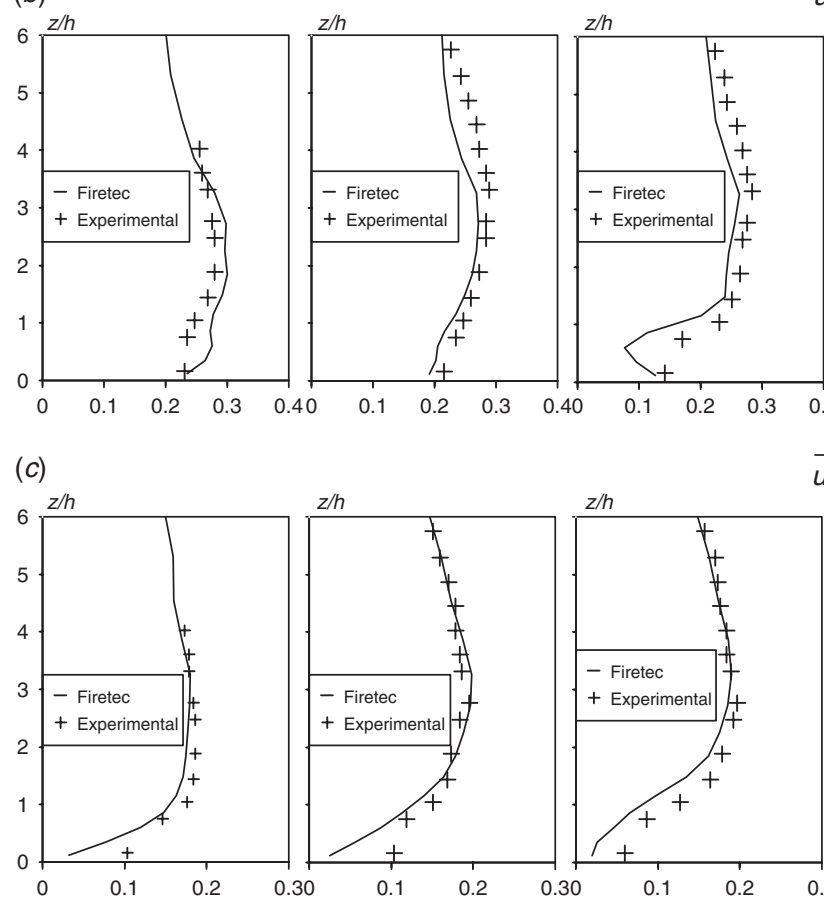

$\frac{\sigma_{u}}{u 2 h}$
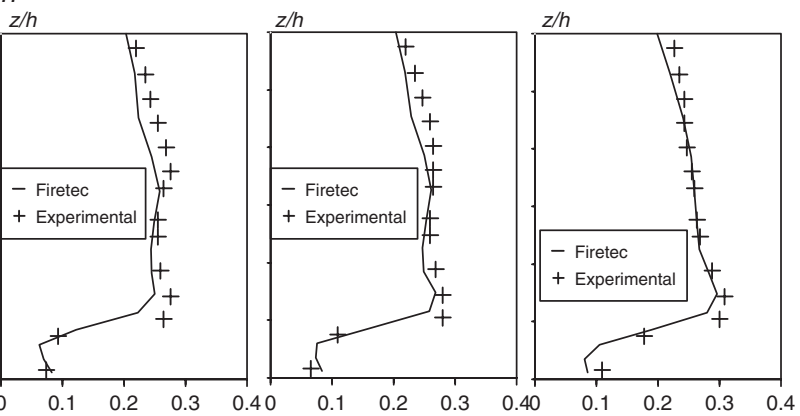

$\frac{\sigma_{v}}{u 2 h}$
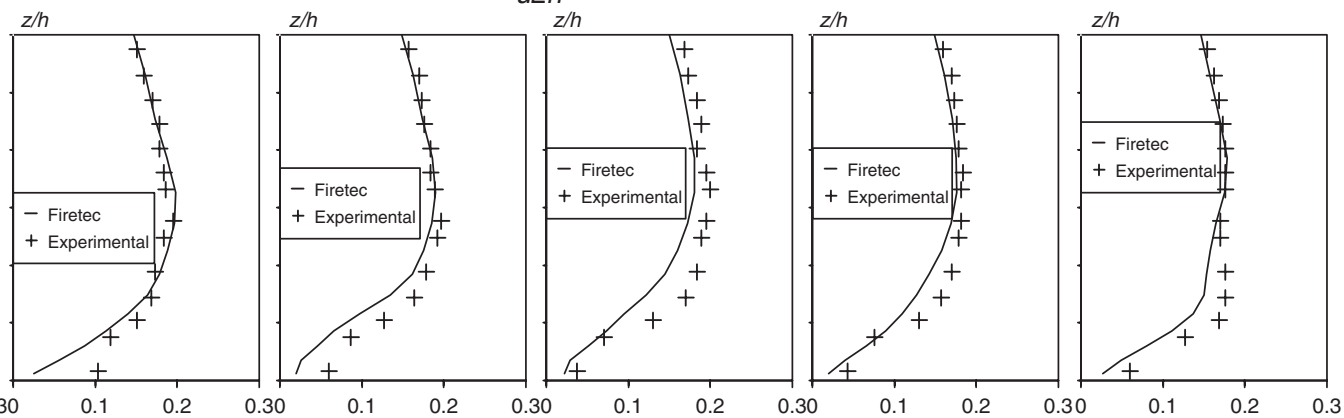

$\frac{\sigma_{w}}{u 2 h}$
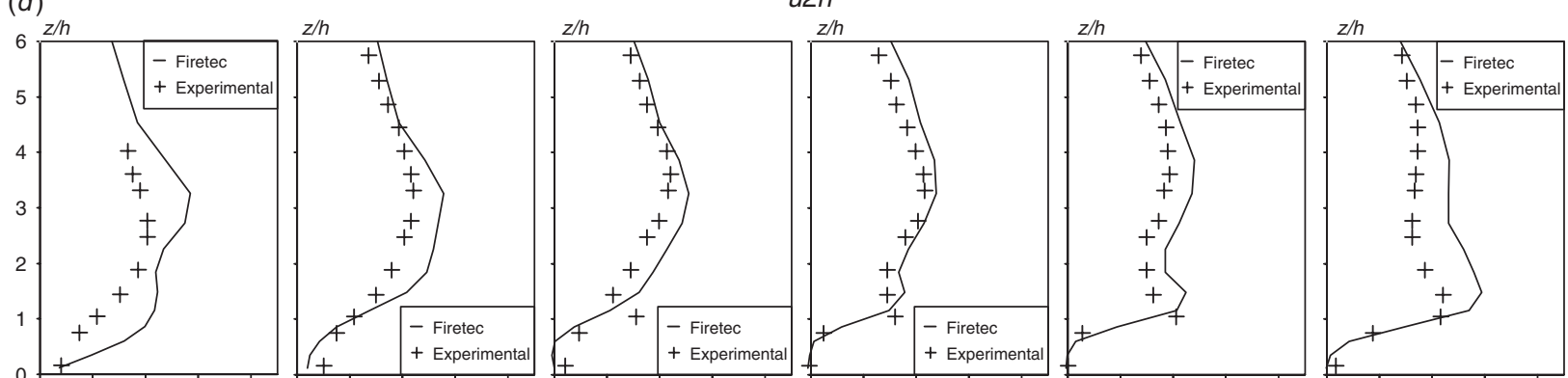

$\begin{array}{llllllllllllllllllllllllllllll}0 & 0.01 & 0.02 & 0.03 & 0.04 & 0 & 0.01 & 0.02 & 0.03 & 0.04 & 0 & 0.01 & 0.02 & 0.03 & 0.04 & 0 & 0.01 & 0.02 & 0.03 & 0.04 & 0 & 0.01 & 0.02 & 0.03 & 0.04 & 0 & 0.01 & 0.02 & 0.03 & 0.04\end{array}$

$$
-\frac{u^{\prime} w_{t o t}^{\prime}}{u 2 h_{t o t}^{2}}
$$

Fig. 7. FIRETEC validation against wind-tunnel observations on a fuel-break-fuel pattern (Raupach et al. 1987). Comparison between the simulated (lines) and observed (crosses) mean profiles of horizontal wind velocity $(a)$; standard deviation of $u(b)$; standard deviation of $w(c)$; and momentum flux $(d)$. The variables are normalized from the mean streamwise wind velocity $u 2 h$ at $x=0 h$ and $z=2 h$. 
fire experiments under the same weather conditions. Moreover, fuel-breaks built for safety reasons in experiments such as the ICFME and other experiments are likely to affect wind characteristics both in magnitude and direction. These fuel-breaks are

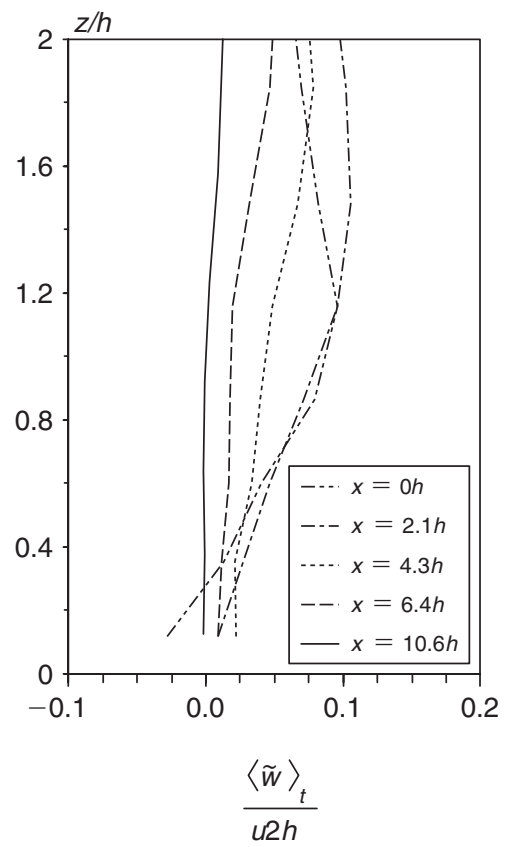

Fig. 8. Simulated mean profiles of vertical wind velocities in the forest at different distances downwind from the leading forest edge: $x=0 h ; x=2.1 h$ $x=4.3 h ; x=6.4 h ; x=10.6 h$. The variables are normalized from the mean streamwise wind velocity $u 2 h$ at $x=0 h$ and $z=2 h$. characterized by an increase of wind velocity and turbulence, as also observed in our simulations. As described in Linn et al. $(2005 b)$ over an experimental plot where the fire propagates (Fig. 13), these higher wind speed on both sides of the experimental plot provide lateral indrafts from the break to the plot that could significantly affect the fire behavior on the sides of the plot and even influence the shape of the fire line at the interior of the plot.

\section{Fuel-break impact on fire propagation}

The design of fuel-breaks raises a paradox: on one hand, they reduce the biomass available, thereby reducing the fire intensity; but on the other hand, they increase the rate of spread owing to the wind velocity increase in the breaks (Rigolot and Costa 2000). This increase of wind velocity is confirmed and quantified by the present studies. There is therefore a need to investigate the role of fuel-breaks on fire propagation depending on break size, ground topography, alignment of fuel break with fireline or wind direction, fuel structure, etc. (Linn et al. 2005a; Pimont et al. 2006; Winterkamp et al. 2006). Pimont et al. (2006) studied the effects of fuel-break cover fraction and heterogeneity size. They showed that reducing cover fraction at stand level could limit crowning activities, but their simulations were performed without precomputation of wind flows. The present study shows that the modifications of the wind-flow velocity and turbulence induced by the presence of a break can be very well described by the physically based model FIRETEC. A fire propagation study including these accurate precomputed flows is still to be done. The present study shows that the model can help to investigate the role of a fuel-break on fire propagation.
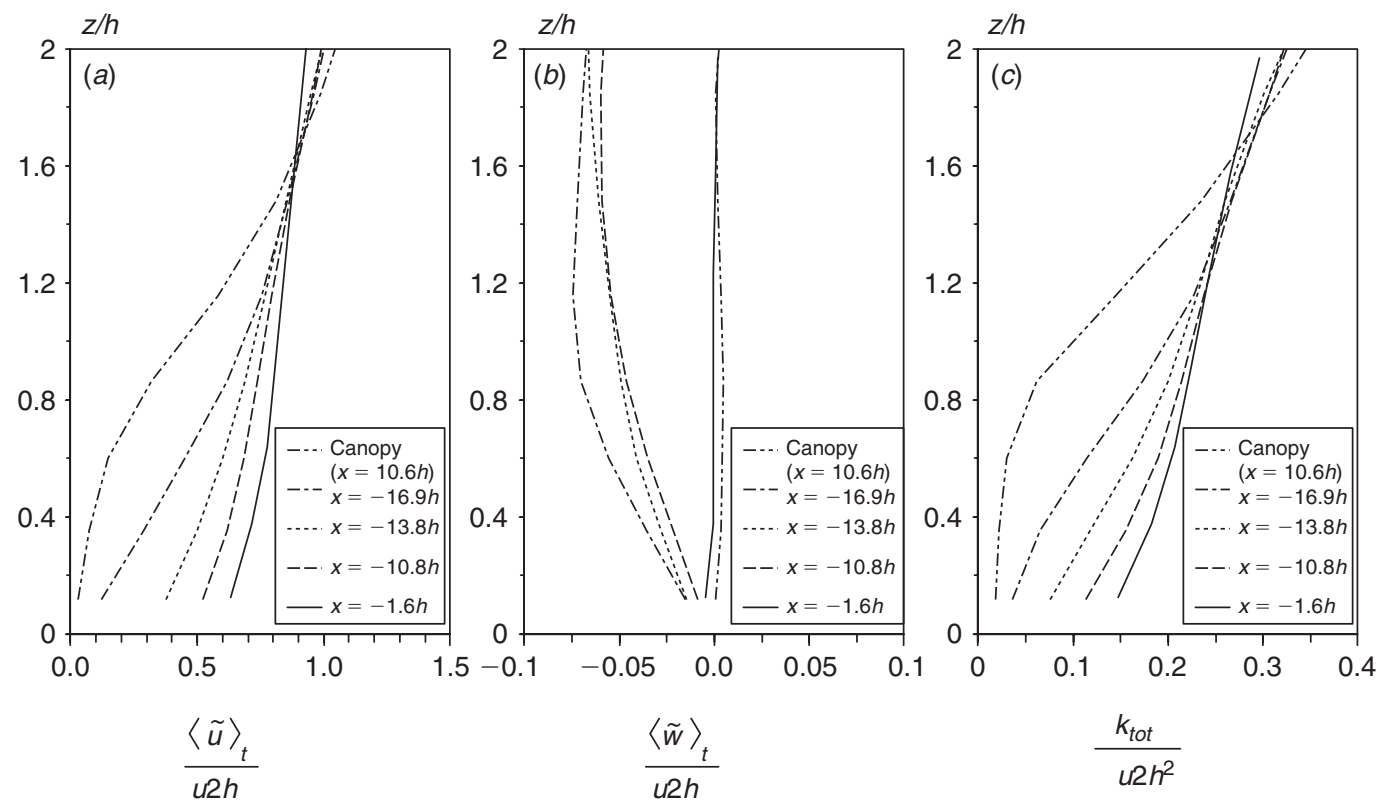

Fig. 9. Simulated mean profiles of horizontal $(a)$ and vertical $(b)$ wind velocities, and turbulent kinetic energy $(c)$ at different positions downwind from the fuel trailing edge $(x=-20 h): x=-16.9 h ; x=-13.8 h ; x=-10.8 h ; x=-1.6 h$. These profiles are respectively taken $20,40,60$ and $120 \mathrm{~m}$ downwind from the fuel trailing edge. The variables are normalized from the mean streamwise wind velocity $u 2 h$ at $x=0 h$ and $z=2 h$ 


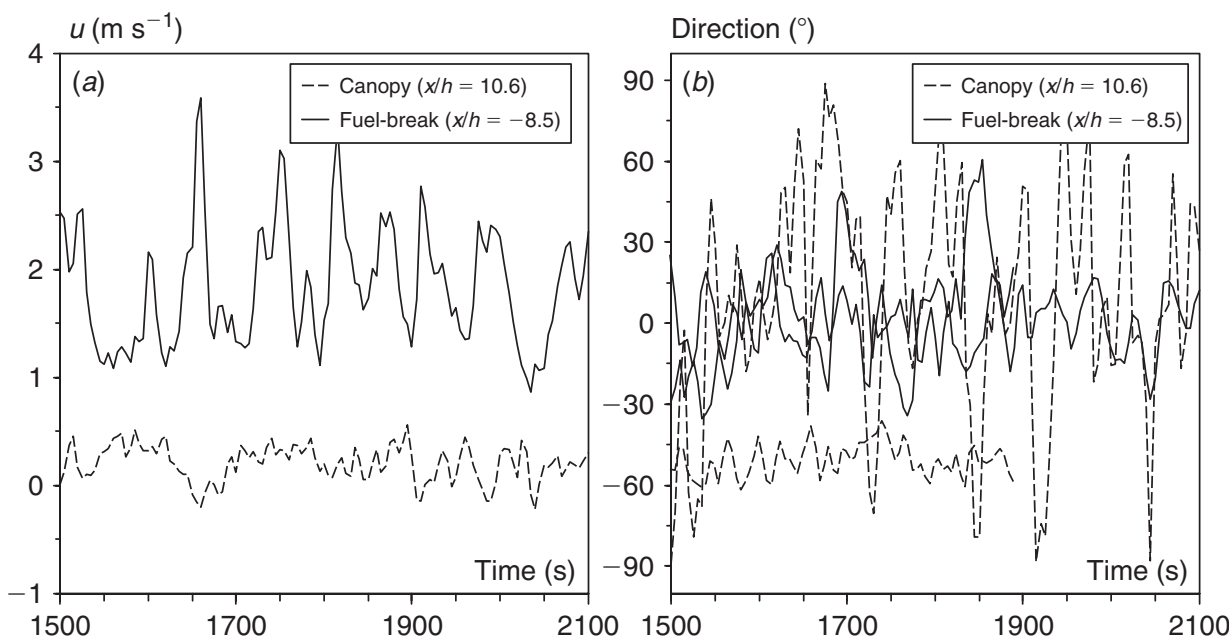

Fig. 10. 10-min time series of the instantaneous wind velocity intensity $(a)$ and direction $(b)$ at $2.3 \mathrm{~m}(0.35 h)$ above the ground within the canopy and within the fuel-break

(a)
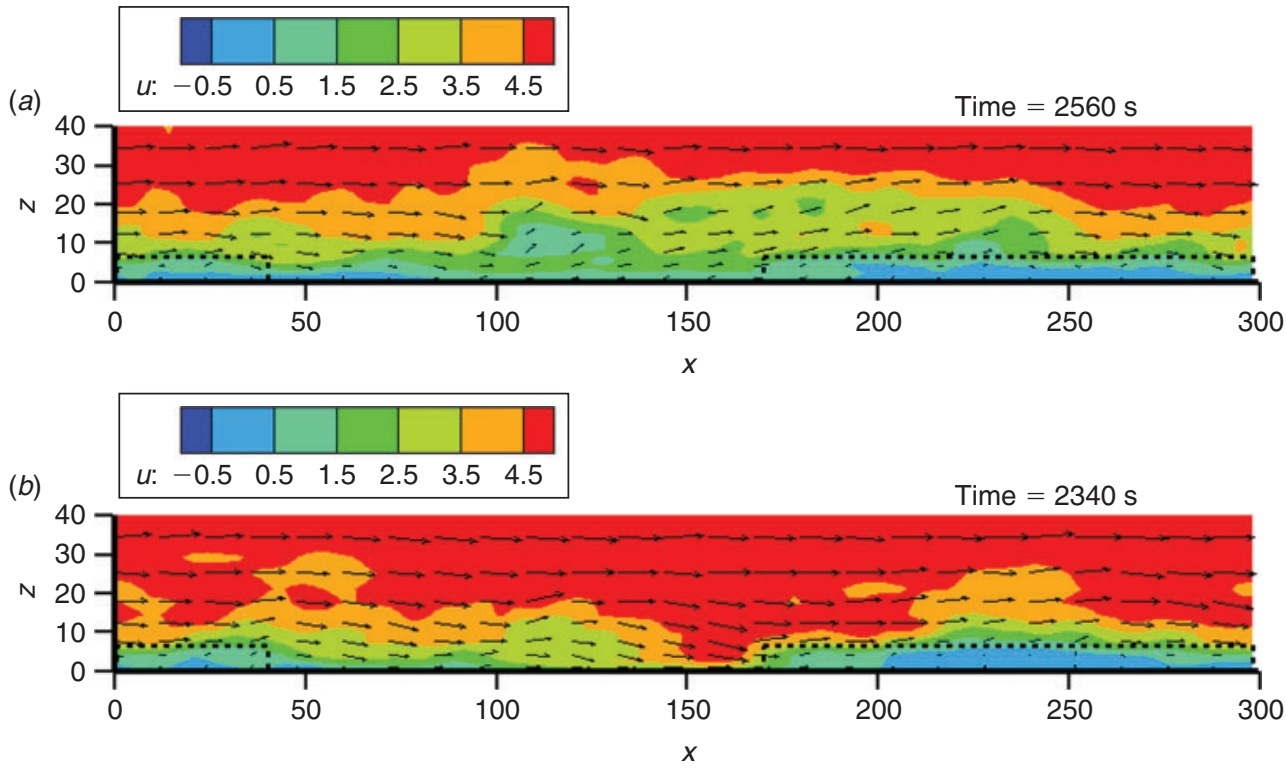

Fig. 11. Instantaneous streamwise wind velocity in a streamwise cross-section over a fuel-break-fuel pattern at two specific times: wind on the break can be low $(a)$ or high $(b)$; the dotted line corresponds to the canopy envelope; $x$ and $z$ are in $\mathrm{m}, u$ in $\mathrm{m} \mathrm{s}^{-1}$.

\section{Conclusion and future works}

The results of the present study are very encouraging. Even though FIRETEC has been primarily designed for fire modelling, it is important that this model is able to capture the main aspects of turbulent flow over heterogeneous canopies because fire propagation is largely controlled by the wind flow. The model validation under neutral conditions presented in this paper illustrates that FIRETEC simulates turbulent flows over canopies with the same accuracy as other air-flow models specifically dedicated to turbulence computation. The wind-flow structure under unstable conditions, in the vicinity of topographic features, or with fire influence is by far less known and has been seldom reproduced with LES models. Further investigations and additional experimental data are needed for validation in this context.

The flows modelled by the FIRETEC model are very realistic, with intermittent large turbulent structures (gusts). At stand or wildland-urban interface scales or at the experimental plot scale, these local gusts and directional changes created by vegetation itself likely have a very significant impact on fire behavior in terms of ROS, lateral ROS and crowning activities. The ability of FIRETEC to reproduce these wind fluctuations is 

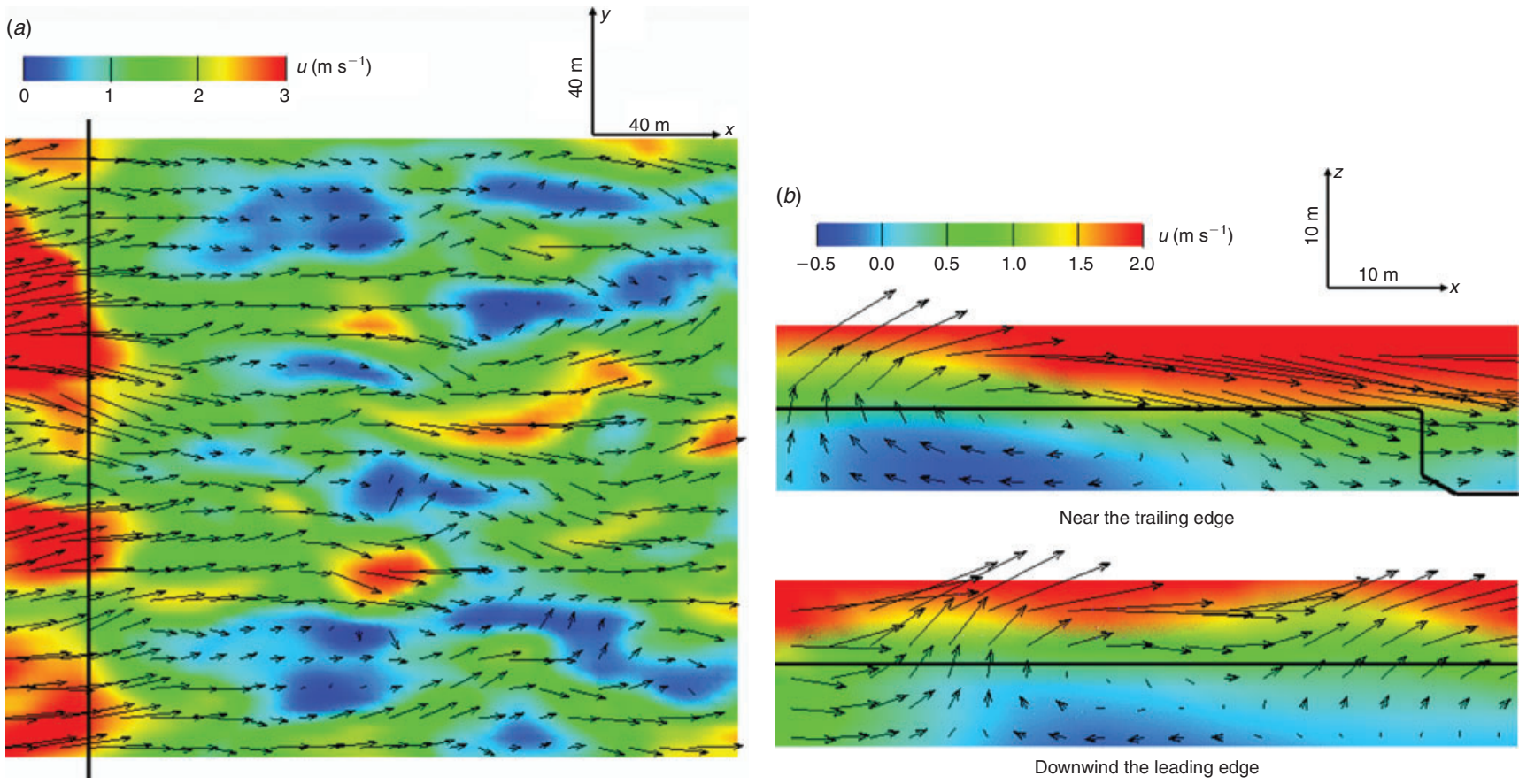

Fig. 12. Instantaneous streamwise wind velocity at time $=2560 \mathrm{~s}$ : top view of the forest area downwind to the leading edge at $z=6.5 \mathrm{~m}(a)$; and side views at $y=75 \mathrm{~m}$, near the trailing edge and downwind to the leading edge $(b)$; the black line corresponds to the canopy envelope.

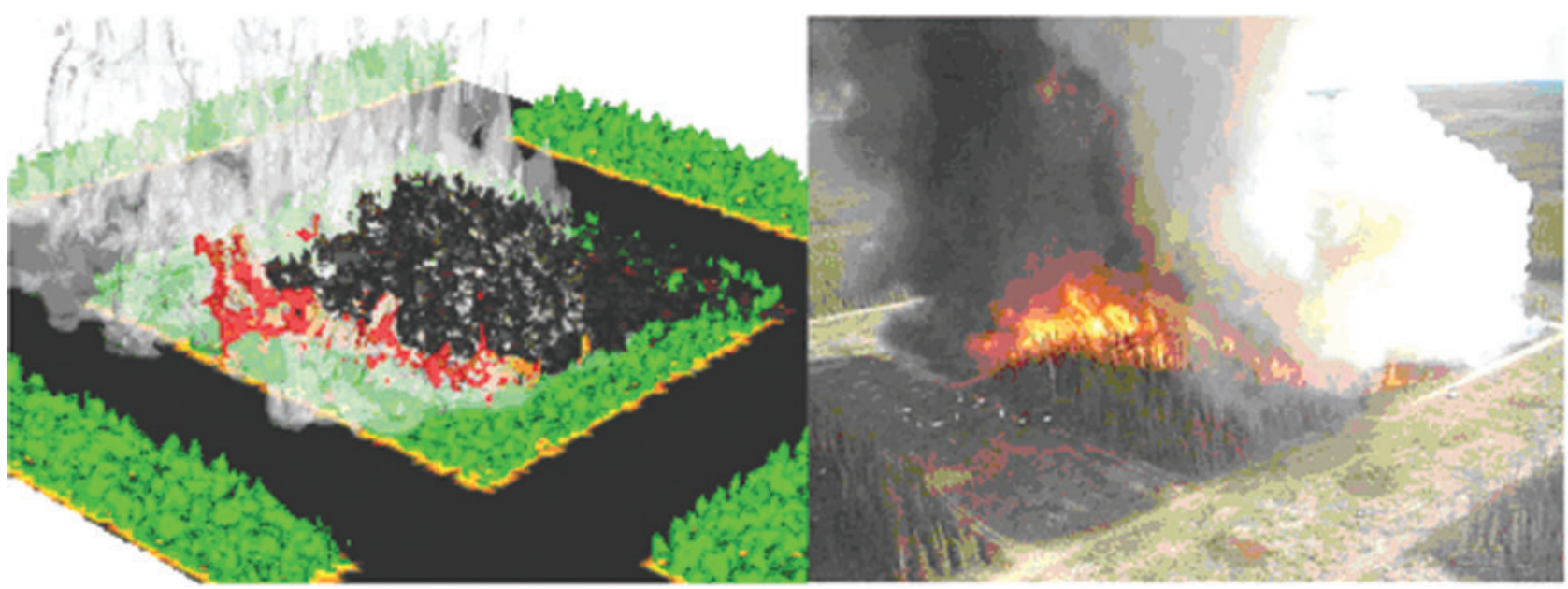

Fig. 13. Comparison of FIRETEC simulation and International Crown Fire Modeling Experiment (ICFME) plot 1 (taken from Linn et al. 2005b). Photographs courtesy of Natural Resources Canada ICFME website, http://fire.cfs.nrcan.gc.ca/research/environment/icfme/photographs_e.htm (accessed 2005).

promising for a better understanding of their influence on fire behavior.

The present study also shows that fuel-break design is not straightforward because even though vegetation treatments might reduce the amount of fuel for a fire to burn, they can also simultaneously result in an increase in the mean wind velocity and gust intensity. Further investigations performed with physics-based wildfire models, such as FIRETEC, would help to understand which fuel structure and which fuel-break design are the most appropriate for reducing fire intensity and severity under various wind conditions.

\section{Nomenclature used in the text}

Latin symbols

$A, B, C$, subscripts related to the length scale of turbulent structures $a_{f}$, leaf area density $\left(\mathrm{m}^{-1}\right)$

$C_{d}$, vegetation drag coefficient 
$C_{P w}$, parameter of the wake production term

$D$, diffusion term of the subgrid-scale (SGS) turbulent kinetic energy $\left(\mathrm{kg} \mathrm{m}^{-1} \mathrm{~s}^{-3}\right)$

$E T_{A \rightarrow B}$, energy transfer from scale $A$ to scale $B\left(\mathrm{~kg} \mathrm{~m}^{-1} \mathrm{~s}^{-3}\right)$

$E T_{B \rightarrow C}$, energy transfer from scale $B$ to scale $C\left(\mathrm{~kg} \mathrm{~m}^{-1} \mathrm{~s}^{-3}\right)$

$F_{d i}$, vegetation drag-force in the $i$ direction $\left(\mathrm{kg} \mathrm{m}^{-1} \mathrm{~s}^{-2}\right)$

$g_{i}$, gravity acceleration (component in the $i$ direction) $\left(\mathrm{m} \mathrm{s}^{-2}\right)$

$h$, main vegetation height $(\mathrm{m})$

$k$, total SGS turbulent kinetic energy $\left(\mathrm{m}^{2} \mathrm{~s}^{-2}\right)$

$k_{A}, k_{B}, k_{C}$, SGS turbulent kinetic energy at scale $A, B, C\left(\mathrm{~m}^{2} \mathrm{~s}^{-2}\right)$

$k_{\text {tot }}$, mean total turbulent kinetic energy $\left(\mathrm{m}^{2} \mathrm{~s}^{-2}\right)$

$P$, pressure $(\mathrm{Pa})$

$P_{S}$, shear production term $\left(\mathrm{kg} \mathrm{m}^{-1} \mathrm{~s}^{-3}\right)$

$P_{W}$, wake production term $\left(\mathrm{kg} \mathrm{m}^{-1} \mathrm{~s}^{-3}\right)$

$R_{i j}$, Reynolds tensor

$s_{A}, s_{B}, s_{C}$, turbulent length scale $A, B$ and $C$

$T$, gas temperature $(\mathrm{K})$

$u, v, w$, wind velocity $\left(\mathrm{m} \mathrm{s}^{-1}\right)$

$u_{1}, u_{2}, u_{3}$, wind velocity $\left(\mathrm{m} \mathrm{s}^{-1}\right)$

$u_{1}^{i n i}, u_{2}^{i n i}, u_{3}^{i n i}$, initial wind velocity $\left(\mathrm{m} \mathrm{s}^{-1}\right)$

$u_{2 h}^{i n i}$, initial wind velocity at $z=2 h\left(\mathrm{~m} \mathrm{~s}^{-1}\right)$

$u 2 h$, velocity at height $h$ and $x / h=0$ in fuel-break case $\left(\mathrm{m} \mathrm{s}^{-1}\right)$

$u^{\prime} w_{\text {tot }}^{\prime}$, mean total momentum flux $\left(\mathrm{m}^{2} \mathrm{~s}^{-2}\right)$

$V T_{c o r r}$, velocity pressure correlation $\left(\mathrm{kg} \mathrm{m}^{-1} \mathrm{~s}^{-3}\right)$

\section{Greek symbols}

$\alpha$, volume fraction (packing ratio)

$\delta_{i j}$, the Kronecker symbol

$\sigma$, area per volume ratio $\left(\mathrm{m}^{-1}\right)$

$\sigma_{h}$, mean total standard deviation of velocity module $\left(\mathrm{m} \mathrm{s}^{-1}\right)$

$\sigma_{u, v, w}$, mean total standard deviations of velocity components $\left(\mathrm{m} \mathrm{s}^{-1}\right)$

$\rho_{g}$, gas density $\left(\mathrm{kg} \mathrm{m}^{-3}\right)$

$\varepsilon$, turbulence dissipation rate $\left(\mathrm{kg} \mathrm{m}^{-1} \mathrm{~s}^{-3}\right)$

$v_{T}$, total turbulent diffusion coefficient $\left(\mathrm{m}^{2} \mathrm{~s}^{-1}\right)$

$v_{T, s}$, total turbulent diffusion coefficient at scale $s\left(\mathrm{~m}^{2} \mathrm{~s}^{-1}\right)$

\section{Acknowledgements}

This study has been partially funded by the European Commission in the frame of the FIREPARADOX research program (contract FP6-018505) and the large computations for this work have been made possible by the Los Alamos National Laboratory Institutional Computing resources.

\section{References}

Alexander ME (1998) Crown fire thresholds in exotic plantations of Australasia. Ph.D. thesis, Australian National University, Canberra.

Amiro BD (1990) Comparison of turbulence statistics within three boreal forest canopies. Boundary-Layer Meteorology 51,99-121. doi:10.1007/ BF00120463

Andrews PL (1986) BEHAVE: fire behaviour prediction and fuel modelling system - BURN subsystem, Part 1. USDA Forest Service, Intermountain Research Station, Research paper INT-194. (Ogden, UT)

Brunet Y, Finnigan JJ, Raupach MR (1994) A wind-tunnel study of air flow in waving wheat: single-point velocity statistics. Boundary-Layer Meteorology 70, 95-132. doi:10.1007/BF00712525

Butler B, Forthofer J, Finney M, McHugh C, Stratton R, Bradshaw L (2006) The impact of high-resolution wind field simulations on the accuracy of fire growth predictions. In 'Proceedings of the 5th International Conference on Forest Fire Research', 27-30 November 2006, Figueira da Foz, Portugal. (Ed. DX Viegas) (Elsevier B.V.: Amsterdam)

Canfield FM, Linn RR, Cunningham P, Goodrick SL (2005) Modelling effects of atmospheric stability on wildfire behaviour. In 'Proceedings 6th Fire and Forest Meteorology Symposium and 19th Interior West Fire Council Meeting', 25-27 October 2005, Canmore, AB, Canada. (American Meteorological Society) [Abstract]

Catchpole WR, Catchpole EA, Butler BW, Rothermel RC, Morris CA, Latham DJ (1998) Rate of spread of free-burning fires in woody fuels in a wind tunnel. Combustion Science and Technology 131, 1-37. doi:10.1080/00102209808935753

Chen JM, Black TA, Novak MD, Adams RS (1995) A wind tunnel study of turbulent airflow in forest clearcuts. In 'Wind and Trees'. (Eds MP Coutts, J Grace) pp. 71-87. (Cambridge University Press: London)

Cheney NP, Gould JS, Catchpole WR (1998) Prediction of fire spread in grasslands. International Journal of Wildland Fire 8(1), 1-13. doi:10.1071/WF9980001

Cruz MG (2004) Ignition of crown fuels above a spreading surface fire. Ph.D. thesis, University of Montana, Missoula

Dupont S, Brunet Y (2006) Simulation of turbulent flow in an urban forested park damaged by a windstorm. Boundary-Layer Meteorology 120, 133-161. doi:10.1007/S10546-006-9049-5

Dupont S, Brunet Y (2007) Edge flow and canopy structure: a large-eddy simulation study. Boundary-Layer Meteorology 126, 51-71. doi:10.1007/ S10546-007-9216-3

Dupont S, Brunet Y (2008a) Influence of foliar density profile on canopy flow: a large-eddy simulation study. Agricultural and Forest Meteorology 148, 976-990. doi:10.1016/J.AGRFORMET.2008.01.014

Finnigan J (2000) Turbulence in plant canopies. Annual Review of Fluid Mechanics 32, 519-571. doi:10.1146/ANNUREV.FLUID. 32.1.519

Foudhil H, Brunet Y, Caltagirone JP (2005) A fine-scale k- $\varepsilon$; model for atmospheric flow over heterogeneous landscapes. Environmental Fluid Mechanics 5(3), 247-265. doi:10.1007/S10652-004-2124-X

Gao W, Shaw RH, Paw UKT (1989) Observation of organised structures in turbulent flow within and above a forest canopy. Boundary-Layer Meteorology 47, 349-377. doi:10.1007/BF00122339

Gillies JA, Nickling WG, King J (2002) Drag coefficient and plant form response to wind speed in three plant species: burning bush (Euonymus alatus), Colorado blue spruce (Picea pungens glauca), and fountain grass (Pennisetum setaceum). Journal of Geophysical Research-Atmospheres 107(D24), 4760. doi:10.1029/2001JD001259D24

Green SR (1992) Modelling turbulence air flow in a stand of widely spaced trees, PHOENICS. Journal of Computational Fluid Dynamics $\mathbf{5}$, 294-312.

Kaimal JC, Finnigan JJ (1994) 'Atmospheric Boundary Layer Flows. Their Structure and Measurements.' (Oxford University Press: New York)

Kanda M, Hino M (1994) Organized structures in developing turbulentflow within and above a plant canopy, using a LES. Boundary-Layer Meteorology 68(3), 237-257. doi:10.1007/BF00705599

Lee X (2000) Air motion within and above forest vegetation in non-ideal conditions. Forest Ecology and Management 135, 3-18. doi:10.1016/ S0378-1127(00)00294-2

Li Z, Lin JD, Miller DR (1990) Air flow over and through a forest edge: a steady-state numerical simulation. Boundary-Layer Meteorology 51, 179-197. doi:10.1007/BF00120467

Linn RR (1997) A transport model for prediction of wildfire behavior. Los Alamos National Laboratory, Science Report LA-13334-T. (Los Alamos, NM)

Linn RR, Cunningham P (2005) Numerical simulations of grass fires using a coupled atmosphere-fire model: basic fire behavior and dependence on wind speed. Journal of Geophysical Research 110, D13107. doi:10.1029/2004JD005597 
Linn RR, Winterkamp J, Colman JJ, Edminster C, Bailey J (2005a) Modeling interactions between fire and atmosphere in discrete element fuel beds. International Journal of Wildland Fire 14,37-48. doi:10.1071/WF04043

Linn RR, Canfield J, Winterkamp J, Cunningham P, Colman JJ, Edminster C, Goddrick SL (2005b) Numerical simulations of fires similar to the International Crown Fire Modeling Experiment. In 'Proceedings 6th Fire and Forest Meteorology Symposium and 19th Interior West Fire Council Meeting', 25-27 October, Canmore, Alberta. (American Meteorological Society) [Abstract]

Linn RR, Reisner J, Colman JJ, Winterkamp J (2002) Studying wildfire behavior using FIRETEC. International Journal of Wildland Fire 11, 233-246. doi:10.1071/WF02007

Liu J, Chen JM, Black TA, Novak MD (1996) E- $\varepsilon$ modelling of turbulent air flow downwind of a model forest edge. Boundary-Layer Meteorology 77, 21-44. doi:10.1007/BF00121857

Lu CH, Fitzjarrald DR (1994) Seasonal and diurnal variations of coherent structures over a deciduous forest. Boundary-Layer Meteorology 69 43-69. doi:10.1007/BF00713294

Morse AP, Gardiner BA, Marshall BJ (2002) Mechanisms controlling turbulence development across a forest edge. Boundary-Layer Meteorology 103, 227-251. doi:10.1023/A:1014507727784

Novak MD, Warland JS, Orchansky AL, Ketler R, Green S (2000) Wind tunnel and field measurements of turbulent flow in forests. Part I: Uniformly thinned stands. Boundary-Layer Meteorology 95, 457-495. doi:10.1023/ A: 1002693625637

Patton EG, Shaw RH, Judd MJ, Raupach MR (1998) Large-eddy simulation of windbreak flow. Boundary-Layer Meteorology 87, 275-307. doi:10.1023/A:1000945626163

Pimont F, Linn RR, Dupuy JL, Morvan D (2006) Effects of vegetation description parameters on forest fire behavior with FIRETEC. Forest Ecology and Management 234(Suppl. 1), S120. doi:10.1016/ J.FORECO.2006.08.161

Pope SB (2000) 'Turbulent Flows.' (Cambridge University Press: Cambridge, UK)

Raupach MR, Coppin PA, Legg BJ (1986) Experiments on scalar dispersion within a model plant canopy. Part I: The turbulence structure. BoundaryLayer Meteorology 35, 21-52. doi:10.1007/BF00117300

Raupach MR, Bradley EF, Ghadiri H (1987) A wind tunnel investigation into aerodynamic effect of forest clearing on the nesting of Abbott's Booby on Christmas Island. CSIRO Marine and Atmospheric Research, Centre for Environmental Mechanics, Technical Report T12. (Canberra, Australia)

Raupach MR, Finnigan JJ, Brunet Y (1996) Coherent eddies and turbulence in vegetation canopies: the mixing-layer analogy. Boundary-Layer Meteorology 78, 351-382. doi:10.1007/BF00120941

Reisner JM, Wynne S, Margolin L, Linn RR (2000a) Coupled atmosphericfire modeling employing the method of averages. Monthly Weather Review 128, 3683-3691. doi:10.1175/1520-0493(2001)129<3683. CAFMET $>2.0 . \mathrm{CO} ; 2$

Reisner JM, Knoll DA, Mousseau VA, Linn RR (2000b) New numerical approaches for coupled atmosphere-fire models. In 'Proceedings of the Third Symposium on Fire and Forest Meteorology', January 2000, Long Beach, CA. pp. 11-14. (American Meteorology Society: Boston, MA)

Rigolot E, Costa M (2000) 'Conception des Coupures de Combustible.' Réseau Coupures de Combustible RCC no. 4. (Editions de la Cardère: Morières, France)
Rothermel RC (1972) A mathematical model for predicting fire spread in wildland fuels. USDA Forest Service, Intermountain Forest and Range Experiment Station, General Technical Report INT-115. (Ogden, UT)

Shaw RH, Patton EG (2003) Canopy element influences on resolved- and subgrid-scale energy within a large-eddy simulation. Agricultural and Forest Meteorology 115, 5-17. doi:10.1016/S0168-1923(02)00165-X

Shaw RH, Schumann U (1992) Large-eddy simulation of turbulent flow above and within a forest. Boundary-Layer Meteorology 61, 47-64. doi:10.1007/BF02033994

Shaw RH, Den Hartog G, Neumann HH (1988) Influence of foliar density and thermal stability on profiles of Reynolds stress and turbulence intensity in a deciduous forest. Boundary-Layer Meteorology 45, 391-409. doi:10.1007/BF00124010

Smith WS, Reisner JM, Kao CYJ (2001) Simulation of flow around a cubical building: comparison with towing-tank data and assessment of radiatively induced thermal effects.Atmospheric Environment 35, 3811-3821. doi:10.1016/S1352-2310(01)00177-7

Smith WS, Brown MJ, DeCroix DS (2002) Evaluation of CFD simulations using laboratory data and urban field experiments. In 'Proceedings of American Meteorological Society 4th Symposium on the Urban Environment', May 2002, Norfolk, VA. LA-UR-02-1099. (American Meteorology Society: Boston, MA)

Smolarkiewicz PK, Margolin LG (1998) MPDATA: a finite-difference solver for geophysical flows. Journal of Computational Physics 140, 459-480. doi:10.1006/JCPH.1998.5901

Su HB, Shaw RH, Paw UKT, Moeng CH, Sullivan PP (1998) Turbulent statistics of neutrally stratified flow within and above a sparse forest from large-eddy simulation and field observations. Boundary-Layer Meteorology 88,363-397. doi:10.1023/A:1001108411184

Su HB, Shaw RH, Paw UKT (2000) Two-point correlation analysis of neutrally stratified flow within and above a forest from large-eddy simulation. Boundary-Layer Meteorology 94, 423-460. doi:10.1023/ A: 1002430213742

Watanabe T (2004) Large-eddy simulation of coherent turbulence structures associated with scalar ramps over plant canopies. Boundary-Layer Meteorology 112, 307-341. doi:10.1023/B:BOUN.0000027912.84492.54

Wilson JD, Flesh TK (1999) Wind and remnant tree sway in forest cutblocks. III. A windflow model to diagnose spatial variation. Agricultural and Forest Meteorology 93, 259-282. doi:10.1016/S0168-1923(98)00121-X

Winterkamp J, Linn RR, Colman J, Smith S, Edminster CB, Weise DR (2006) Interaction between wildfires, atmosphere, and topography. In 'Proceedings of the 5th International Conference on Forest Fire Research', 27-30 November 2006, Figueira da Foz, Portugal. (Ed. DX Viegas) (Elsevier B. V.: Amsterdam)

Yang B, Raupach M, Shaw RH, Paw UKT, Morse AP (2006a) Large-eddy simulation of turbulent flows across a forest edge. Part I: Flow statistics Boundary-Layer Meteorology 120, 377-412. doi:10.1007/S10546-0069057-5

Yang B, Morse AP, Shaw RH, Paw UKT (2006b) Large-eddy simulation of turbulent flow across a forest edge. Part II: Momentum and turbulence kinetic energy budgets. Boundary-Layer Meteorology 121, 433-457. doi:10.1007/S10546-006-9083-3

Manuscript received 7 September 2007, accepted 22 December 2008 
Appendix 1. Formulation of the different terms of the subgrid-scale (SGS) turbulent kinetic energy (TKE) equations for scales A (Eqn 6) and B (Eqn 7)

\begin{tabular}{llll}
\hline Terms & Designation & Scale A & Scale B \\
\hline$D K$ & Diffusion of energy & $D_{A}=\frac{\partial}{\partial x_{j}}\left[\rho_{g} \nu_{T} \frac{\partial K_{A}}{\partial x_{j}}\right]$ & $D_{B}=\frac{\partial}{\partial x_{j}}\left[\rho_{g} \nu_{T} \frac{\partial K_{B}}{\partial x_{j}}\right]$ \\
$P_{S}$ & Shear production & $P_{S, A}=\left(\rho_{g} \nu_{T, A}\left(\frac{\partial \tilde{u}_{i}}{\partial x_{l}}+\frac{\partial \tilde{u}_{l}}{\partial x_{i}}\right)-\frac{2}{3} \delta_{i l}\left(\rho_{g} \nu_{T, A} \frac{\partial \tilde{u}_{k}}{\partial x_{k}}+\rho_{g} K_{A}\right)\right) \frac{\partial \tilde{u}_{i}}{\partial x_{x}}$ & $P_{S, B}=\left(\rho_{g} v_{T, B}\left(\frac{\partial \tilde{u}_{i}}{\partial x_{l}}+\frac{\partial \tilde{u}_{l}}{\partial x_{i}}\right)-\frac{2}{3} \delta_{i l}\left(\rho_{g} \nu_{T, B} \frac{\partial \tilde{u}_{k}}{\partial x_{k}}+\rho_{g} K_{B}\right)\right) \frac{\partial \tilde{u}_{i}}{\partial x_{l}}$ \\
$E T$ & Energy transfer & $E T_{A \rightarrow B}=4 \rho_{g} C_{d} a_{f} \sqrt{\tilde{u}_{j} \tilde{u}_{j} k_{A}}$ & $E T_{B \rightarrow C}=4 \rho_{g} C_{d} a_{f} \sqrt{\tilde{u}_{j} \tilde{u}_{j} k_{B}}$ \\
$\bullet$ & Dissipation rate & $\varepsilon_{A}=\rho_{g} \frac{\sqrt{k}}{S_{A}} k_{A}$ & $\varepsilon_{B}=\rho_{g} \frac{\sqrt{k}}{S_{B}} k_{B}$ \\
& (free air) & & $\rho_{g} C_{P w} C_{d} a_{f}\left[\tilde{u}_{j} \tilde{u}_{j}\right]^{3 / 2 \mathrm{~A}}$ \\
$P_{W}$ & Wake production & & \\
\hline
\end{tabular}

${ }^{\mathrm{A}} C_{P w}$ is a parameter that has been discussed by several authors. It varies from 0.8 (Foudhil et al. 2005) to 1.0 in most cases (Liu et al. 1996; Shaw and Patton 2003). In our simulations, we chose it equal to 1 . 